\title{
Prospective Use of Brown Spider Venom Toxins as Therapeutic and Biotechnological Inputs
}

Luiza Helena Gremski ${ }^{1}$, Fernando Hitomi Matsubara ${ }^{1}$, Nayanne Louise Costacurta Polli ${ }^{1}$, Bruno Cesar Antunes ${ }^{1,2}$, Pedro Henrique de Caires Schluga ${ }^{1}$, Hanna Câmara da Justa ${ }^{1}$, João Carlos Minozzo ${ }^{2}$, Ana Carolina Martins Wille ${ }^{3}$, Andrea Senff-Ribeiro ${ }^{1}$ and Silvio Sanches Veiga ${ }^{1 *}$

${ }^{1}$ Department of Cell Biology, Federal University of Paraná, Curitiba, Brazil, ${ }^{2}$ Production and Research Center of Immunobiological Products, State Department of Health, Piraquara, Brazil, ${ }^{3}$ Department of Structural, Molecular Biology and Genetics, State University of Ponta Grossa, Ponta Grossa, Brazil

Brown spider (genus Loxosceles) venoms are mainly composed of protein toxins used for predation and defense. Bites of these spiders most commonly produce a local dermonecrotic lesion with gravitational spread, edema and hemorrhage, which together are defined as cutaneous loxoscelism. Systemic loxoscelism, such as

OPEN ACCESS

Edited by:

Maria Elena De Lima, Grupo Santa Casa BH, Brazil

Reviewed by:

Steve Peigneur,

KU Leuven, Belgium

Wagner Ferreira Dos Santos, University of São Paulo Ribeirão Preto,

Brazil

*Correspondence:

Silvio Sanches Veiga veigass@ufpr.br

Specialty section:

This article was submitted to

Cellular Biochemistry,

a section of the journal

Frontiers in Molecular Biosciences

Received: 07 May 2021 Accepted: 04 June 2021 Published: 17 June 2021

Citation:

Gremski LH, Matsubara FH, Polli NLC, Antunes $B C$, Schluga PHdeC, Justa HCda, Minozzo JC, Wille ACM, Senff-Ribeiro $A$ and Veiga SS (2021) Prospective Use of Brown Spider Venom Toxins as Therapeutic and

Biotechnological Inputs.

Front. Mol. Biosci. 8:706704. doi: 10.3389/fmolb.2021.706704 hematological abnormalities and renal injury, are less frequent but more lethal. Some Loxosceles venom toxins have already been isolated and extensively studied, such as phospholipases $D$ (PLDs), which have been recombinantly expressed and were proven to reproduce toxic activities associated to the whole venom. PLDs have a notable potential to be engineered and converted in non-toxic antigens to produce a new generation of antivenoms or vaccines. PLDs also can serve as tools to discover inhibitors to be used as therapeutic agents. Other Loxosceles toxins have been identified and functionally characterized, such as hyaluronidases, allergen factor, serpin, TCTP and knottins (ICK peptides). All these toxins were produced as recombinant molecules and are biologically active molecules that can be used as tools for the potential development of chemical candidates to tackle many medical and biological threats, acting, for instance, as antitumoral, insecticides, analgesic, antigens for allergy tests and biochemical reagents for cell studies. In addition, these recombinant toxins may be useful to develop a rational therapy for loxoscelism. This review summarizes the main candidates for the development of drugs and biotechnological inputs that have been described in Brown spider venoms.

Keywords: Loxosceles, proteins, peptides, recombinant proteins, venom

\section{INTRODUCTION}

Brown spiders are well-adapted arthropods with more than 150 species distributed in all continents (World Spider Catalog. Version 22.0, 2021). In many places, the accidents with these venomous spiders are considered a public health issue, such as in some regions of South America (Da Silva et al., 2004). Few countries have a compulsory notification system that collect the number of cases of loxoscelism, which is why the number of cases around the world is probably underestimated (Lopes et al., 2020). Even in Brazil, which has a suitable notification system, this amount is possibly underrated mainly because the causative specimen is usually not identified. Nevertheless, almost 
8,800 accidents with Brown spiders were reported in Brazil in 2019 and more than $80 \%$ of these cases occurred in the Southern region of Brazil. Between 2010 and 2019, almost 80,000 accidents were reported in Brazil (Ministério da Saúde, 2020). In Mexico, envenomation caused by Loxosceles spider bites is considered a public health problem as about 3,000 accidents with these spiders are annually reported (Sanchez-Olivas et al., 2011). These spiders are not aggressive and their bites usually occur when these animals feel threatened after being compressed against the skin (Futrell, 1992). Loxosceles spiders are small animals that produce minute amounts of venom. They use their venom primarily to kill or paralyze their prey-usually insects-and to deter possible predators, such as human beings (De Castro et al., 2004; Hogan et al., 2004; Chaim et al., 2011). The toxins that comprise this potent venom are highly active against mammalian tissues and trigger local and systemic signs that can vary widely. Victims usually develop a cutaneous lesion near the bite site with initial edema, erythema and itching followed by dermonecrosis with a gravitational spread, which is the hallmark of loxoscelism. The emergence of a systemic commitment is less frequent but is the main cause of deaths. Acute renal failure and hematological disturbances, such as intravascular hemolysis, figure as the major systemic complications of loxoscelism (Da Silva et al., 2004).

Loxoscelism is related to the biological activity of a range of toxins present in the brown spider venoms. Most of these toxins are peptides and proteins mostly exhibiting molecular masses between 5-40 kDa (Veiga et al., 2000; Gremski et al., 2010). One family of enzymes, the phospholipases $\mathrm{D}$, is responsible for most local and systemic effects seen after envenoming. They cleave various types of phospholipids and generate biologically active lipids, which, after all, cause an exacerbated inflammatory response and tissue damage (Gremski et al., 2020). Astacinlike metalloproteases and hyaluronidases are also present. They target extracellular matrix (ECM) components such as fibronectin, entactin, proteoglycans and hyaluronan. Hyaluronidases are involved in the noxious activity of Brown spider venoms by acting as spreading factors of other toxins, enhancing, for example, the gravitational spread of dermonecrotic lesion (Ferrer et al., 2013). A Translationally Controlled Tumor Protein (TCTP) is also part of the venom, and acts as a histamine-releasing factor. Together with an allergen from the cysteine-rich secretory protein (CRISP) family, TCTP contributes to the allergic and inflammatory response of cutaneous loxoscelism (Sade et al., 2012; Boia-ferreira et al., 2019; Justa et al., 2020). A serine protease inhibitor from the Serpin superfamily was also described in a Loxosceles venom and, although its role as a toxin remains to be elucidated, the biological activities of this inhibitor indicate a great potential for drug development (Graeff et al., 2019). A great amount of knottins is also reported and, although their role in loxoscelism remains unknown, their insecticidal activity was already proved, which makes these molecules promising candidates as agents for the control of insect pests (Matsubara et al., 2017).

General data acquired from venom gland transcriptomes and venom proteomes elucidated the toxins' expression profile of many Loxosceles species (Machado et al., 2005; FernandesPedrosa et al., 2008; Dos Santos et al., 2009; Gremski et al.,
2010; Trevisan-Silva et al., 2017; Calabria et al., 2019). In addition, these screening efforts allowed the description of coding sequences of less expressed toxins, which enabled the production of these molecules as recombinant proteins (Sade et al., 2012; Ferrer et al., 2013; Graeff et al., 2019; Justa et al., 2020; De-Bona et al., 2021). In fact, some toxins, such as wild-type and mutated/inactive phospholipases D and astacin-like metalloproteases were recombinantly expressed before the first screening reports (Fernandes Pedrosa et al., 2002; Kalapothakis et al., 2002; Chaim et al., 2006; Da Silveira et al., 2007; Kusma et al., 2008). However, the production of other recombinant proteins, i.e., hyaluronidases, TCTP, ICK peptides, allergen and serpin, was only possible after the initial descriptions of their coding sequences (Sade et al., 2012; Ferrer et al., 2013; Matsubara et al., 2017; Graeff et al., 2019; Justa et al., 2020). Recombinant chimeric proteins consisting of Loxosceles toxins' epitopes were also produced (Mendes et al., 2013; Lima et al., 2018; Souza et al., 2018; Calabria et al., 2019). The expression model differs for each recombinant Loxosceles toxin since some of them are produced as soluble and active proteins by prokaryotic expression systems, while others require a more complex model to achieve the desired production protocol (Boia-ferreira et al., 2019; Graeff et al., 2019; Gremski et al., 2020; Justa et al., 2020; De-Bona et al., 2021). As the purification of toxins from Brown spider venoms usually yields tiny amounts of proteins, the production of recombinant toxins allowed their further characterization. Due to this massive characterization of Loxosceles venom components and to the possibility of producing them as recombinant proteins, these molecules have proven to be valuable tools for their application as antigens to produce improved antivenoms and a vaccine, and as useful scaffolds for the development of specific inhibitors, drugs and biological agents.

\section{A RATIONAL THERAPY FOR LOXOSCELISM BASED ON VENOM PROTEINS}

Although accidents with Brown spiders are frequent and occasionally severe, a definitive treatment for loxoscelism is not well established. As depicted in Table 1, a few therapies are available to manage patients with loxoscelism. As shown, Loxosceles antivenom is the only specific treatment against loxoscelism and its use is the standard recommendation in several countries (Lévano and Fernández, 2004; Ministerio de Salud, 2012; Bermúdez-Méndez et al., 2018; Ministério da Saúde, 2020). However, experimental studies with commercial products are limited to animals, and demonstrate that antivenom reduces cutaneous lesions in rabbits and protects mice of lethality induced by venom (Gomez et al., 1999; Pauli et al., 2009; Fingermann et al., 2020). Currently, clinical studies with available antivenoms are scarce (Fingermann et al., 2020) and some difficulties to produce them are reported. Spider capture and venom extraction, for instance, are laborious and expensive procedures that restrict the antivenom production. In addition, animal suffering is a common inconvenience in the immunization process. 
TABLE 1 | Available therapies used to treat loxoscelism-summarization of their features and basic references on the matter.

\begin{tabular}{|c|c|c|c|c|}
\hline Available therapies & Purpose & Target & Limitations & References \\
\hline $\begin{array}{l}\text { Anti-inflammatory drugs_-mainly } \\
\text { dapsone (topic and oral) }\end{array}$ & $\begin{array}{l}\text { Reduce the massive inflammatory } \\
\text { reaction mainly triggered by venom } \\
\text { PLDs and refrain the development of } \\
\text { dermonecrosis }\end{array}$ & Cutaneous lesion & $\begin{array}{l}\text { Non-specific } \\
\text { Adverse effects of dapsone, such as } \\
\text { anemia, colostasic jaundice, hepatitis, } \\
\text { leukopenia, which can be difficult to } \\
\text { differentiate as drug effect versus } \\
\text { potential visceral compromise of the } \\
\text { bite }\end{array}$ & $\begin{array}{l}\text { (Manríquez and Silva. } \\
\text { (2009), Miranda et al. } \\
\text { (2021)) }\end{array}$ \\
\hline Hyperbaric oxygen therapy & $\begin{array}{l}\text { Treat nonhealing wounds caused by } \\
\text { Loxosceles venom }\end{array}$ & Cutaneous lesion & $\begin{array}{l}\text { Non-specific } \\
\text { Aims only patients with nonhealing } \\
\text { wounds } \\
\text { High-cost method, not often available }\end{array}$ & $\begin{array}{l}\text { (Beilman et al. (1994), } \\
\text { Hobbs et al. (1996)) }\end{array}$ \\
\hline Antibiotics & Manage possible secondary infection & Cutaneous lesion & $\begin{array}{l}\text { Non-specific } \\
\text { Does not prevent the development of } \\
\text { the normal lesion induced by the } \\
\text { venom }\end{array}$ & (Miranda et al. (2021)) \\
\hline Therapeutic plasma exchange & $\begin{array}{l}\text { Removes molecular components from } \\
\text { the blood, possibly molecules related } \\
\text { to the complement system }\end{array}$ & Systemic injury & $\begin{array}{l}\text { Non-specific } \\
\text { Targeted to specific patients, such as } \\
\text { those presenting hemolysis } \\
\text { Needs further investigation } \\
\text { High-cost method }\end{array}$ & $\begin{array}{l}\text { (Said et al. (2014); } \\
\text { Abraham et al. (2015)) }\end{array}$ \\
\hline $\begin{array}{l}\text { Antiloxoscelic serum produced with } \\
\text { venoms of Loxosceles gaucho, L. } \\
\text { intermedia and L. laeta and } \\
\text { Antiarachnidic serum produced with } \\
\text { venoms of } L \text {. gaucho, Phoneutria } \\
\text { nigriventer and Tityus serrulatus }\end{array}$ & $\begin{array}{l}\text { Neutralize circulating venom toxins, } \\
\text { reducing their action upon target } \\
\text { tissues, such as kidneys, blood and } \\
\text { liver }\end{array}$ & $\begin{array}{l}\text { Systemic injury } \\
\text { (main) and } \\
\text { Cutaneous lesion }\end{array}$ & $\begin{array}{l}\text { Efficacy depends on early application } \\
\text { (up to } 6 \mathrm{~h} \text { after the bite) } \\
\text { High-cost method } \\
\text { Animal welfare issues along the } \\
\text { production process } \\
\text { Present side effects that vary from } \\
\text { rashes to severe adverse reactions } \\
\text { (anaphylaxis, anaphylactoid reactions, } \\
\text { serum sickness and death) }\end{array}$ & $\begin{array}{l}\text { (Barbaro et al. (1996), De } \\
\text { Almeida et al. (2008), } \\
\text { Pauli et al. (2009)) }\end{array}$ \\
\hline
\end{tabular}

Considering this, the search for novel therapies and new methods of antivenom production are required and, fortunately, technological innovation is a reality that will certainly contribute to this improvement.

\section{Antivenom and Monoclonal Antibodies for the Treatment of Loxoscelism}

The use of serum therapy to manage patients bitten by venomous animals dates from the last decades of the 19th century (Calmette, 1986; Hawgood, 1992; Pucca et al., 2019). Despite the advancements, current Loxosceles antivenoms are still based on plasma-derived fragments of immunoglobulins from animals hyper-immunized with venom. Since the purification of large amounts of venom is one of the major hitches in this process, the first efforts to use recombinant toxins as immunogens were made. As phospholipases D (PLDs) can trigger most of the toxic effects caused by crude venom, the first studies focused on these toxins to replace the venom in the antivenom production (Chaim et al., 2006; Kusma et al., 2008; Chaves-Moreira et al., 2009, 2011; Gremski et al., 2014, 2020; da Silva et al., 2021).

The PLD/smase I from L. laeta was the first recombinant toxin used as an antigen in an immunization protocol using rabbits. The antiserum raised against this toxin blocked the development of dermonecrosis induced by $L$. laeta venom in rabbits (Fernandes Pedrosa et al., 2002). In addition, a mixture of recombinant PLDs of two North American species L. reclusa (Lr1N), and L. boneti (Lb1C), and one South American species $L$. laeta (L11N; L12C) was later tested (Olvera et al., 2006). Comparative analyses between the commercial Peruvian antivenom, produced by hyperimmunization of horses with $L$. laeta (Peru) venom, and a serum produced by hyperimmunization of horses with a PLD of $L$. intermedia (Brazil) (rLiD1) demonstrated a limited protection when only the recombinant toxin was used as antigen. The anti-venom performed $100 \%$ of protection against the lethality in mice induced by L. laeta and L. intermedia venoms. Nevertheless, while anti-PLD serum fully protected the animals from $L$. intermedia venom, a partial protection (75\%) was observed against L. laeta venom (Duarte et al., 2015). Both sera completely neutralized the dermonecrotic and hemorrhagic activities, but partially inhibited the edematogenic activity of $L$. laeta venom in rabbits (Duarte et al., 2015).

In 2008, the production and purification of a polyvalent serum produced in horses with PLDs from L. intermedia ( $\mathrm{rP} 1$ and $\mathrm{rP} 2$ ) and from L. laeta (smase I) were patented (patent 0404765-6 INPI) (De Almeida et al., 2008). The efficacy of this serum in reducing dermonecrotic lesions was compared to the commercial anti-arachnid serum (produced in horses with a mixture of venoms from Loxosceles gaucho, Phoneutria nigriventer and Tityus serrulatus). The anti-PLD serum showed to be more active than anti-arachnidic serum against dermonecrosis and hemolysis caused by L. intermedia and L. laeta venoms and had the same protection against the venom of $L$. gaucho (De Almeida et al., 2008). A recombinant PLD of L. gaucho (LgRec1) also demonstrated to be highly immunogenic, and the previous 
incubation of the sera from rabbits immunized with this protein fully inhibited dermonecrosis triggered by L. gaucho venom (Magalhães et al., 2013). These studies showed that PLDs are good candidates to replace crude venoms for antivenom production. However, it is important to highlight that Loxosceles venoms are composed by diverse homologous isoforms of PLDs and other molecules that may play an important role in the cutaneous and systemic loxoscelism. In addition, the cross-neutralization is not observed among PLDs from all Loxosceles species. Finally, active PLDs are toxic to the injected animals and, as with the venom, continuous immunizations with these proteins can greatly affect the health of immunized animals and reduce their lifespan.

In this regard, efforts have been made to improve the protocol of immunization. The use of synthetic peptides with amino acid sequences corresponding to epitopes or antigenic regions of toxins could also be applied to antivenom preparation. For instance, antigenic regions of a PLD of L. intermedia (LiD1) were synthesized and used to immunize rabbits. The purified IgG pre-incubated with LiD1 reduced dermonecrotic, hemorrhagic and edema activities of this protein by 82,35 and $35 \%$ respectively, but the co-immunization of these peptides with LiD1 improved the neutralization capacity of IgGs against LiD1. However, the protection against the venom was not evaluated (Felicori et al., 2009). One chimeric protein (Lil) containing epitopes of L. intermedia, L. laeta and L. gaucho PLDs was also tested as an immunogen. Around $40 \%$ of necrosis, hemorrhage and edema were neutralized when $L$. intermedia venom was preincubated with anti-Lil serum (Souza et al., 2018). Better results were found when a recombinant chimeric protein (rCpLi) formed by a fusion of three epitopes of $\mathrm{LiD} 1$ was used: the previous incubation of anti-rCpLi IgG with rLiD1 partially neutralized its dermonecrotic (95\%), hemorrhagic (75\%) and edematogenic (10\%) effects (Mendes et al., 2013). An immunization schedule in horses that combined $\mathrm{rCpLi}$ and Loxosceles venoms as immunogens produced sera that fulfilled the efficacy tests (100\% of reduction in dermonecrosis elicited by $L$. intermedia venom in rabbits). The protocol included three initial injections of a mixture of L. intermedia, L. laeta and L. gaucho venoms, six additional injections with $\mathrm{rCpLi}$ and a reimmunization schedule consisting of three boosters of the venom mixture. The sera of horses that received only $\mathrm{rCpLi}$ on immunizations performed around $50 \%$ of reduction in dermonecrosis (Figueiredo et al., 2014). As mentioned earlier, loxoscelic venoms have other proteins that play a role in loxoscelism, i.e., metalloproteinases, serine proteases, hyaluronidases, TCTP and allergens (Feitosa et al., 1998; Veiga et al., 2000; Da Silveira et al., 2007; Trevisan-Silva et al., 2010; Ferrer et al., 2013; Justa et al., 2020; De-Bona et al., 2021). Thus, the inclusion of these toxins in the production of sera turns out to be a strategy to enhance the efficacy of antivenoms. Therefore, recombinant chimeric proteins containing selected epitopes of some of these proteins were created. For instance, epitopes from a smase I of L. laeta, a metalloprotease (LALP-1) and a hyaluronidase (LiHyal) of L. intermedia were fused with $\mathrm{rCpLi}$ forming a multiepitope chimeric protein (rMEPLox) which was used as an immunogen in rabbits. Previous incubation of
anti-rMEPLox sera protected $60 \%$ of mice from lethal effects of $L$. intermedia venom (Lima et al., 2018). In addition, pre-incubation of this venom with anti-rMEPLox IgGs reduced $60 \%$ of the hyaluronidase activity of venom (Lima et al., 2018). Another chimeric protein (LgRec1ALP1) which included antigenic regions of a PLD (LgRec1) and a metalloprotease (LgALP1) of L. gaucho venom was also evaluated as antigen (Calabria et al., 2019). Previous incubation of anti-LgRec1ALP IgGs with the venoms of $L$. gaucho, $L$. intermedia, $L$. laeta reduced the dermonecrotic effects of these venoms in 100, 79 and $68 \%$, respectively (Calabria et al., 2019). In vitro, those IgGs reduced the platelet aggregation and the proteolytic action of metalloproteases of the three venoms (Calabria et al., 2019).

Despite the use of chimeric proteins and linear epitopes with antigenic regions in immunization protocols has demonstrated promising results, structural analyses of epitope-antibody interactions have shown that over $90 \%$ of epitopes in proteins are conformational and do not react with any peptide fragment derived from the parent protein (Van Regenmortel, 1996). In this sense, the recombinant expression of PLDs, which is wellestablished, allowed the production of non-toxic molecules that may nonetheless elicit protective humoral responses while minimizing envenomation and suffering of animals used in antivenom production. The fusion of a $\beta$-galactosidase tag with a PLD (Li-rec) eliminated its toxicity; the application of this protein as an immunogen produced a serum that neutralized 2.5 LD50 of L. intermedia venom per $\mathrm{ml}$ of serum in a murine lethality model (Kalapothakis et al., 2002; Araujo et al., 2003). Comparative analyses between the protection of animals immunized with recombinant active (rLlPLD1) or inactive (rLlPLD2) isoforms of L. laeta PLDs showed that both protocols reduced the development of dermonecrotic lesions induced by L. laeta venom at similar levels, thus reinforcing that the antigenic potential of these enzymes is not related to their activity (Catalán et al., 2011). Molecular engineering enabled the production of mutated PLDs from $L$. intermedia, L. laeta and L. gaucho venoms with appropriate conformational structure, but devoid of enzymatic activity, opening the possibility to apply these proteins as immunogens to the development of antivenoms or vaccines (Vuitika et al., 2016; da Silva et al., 2021). Figure 1 illustrate this potential of such toxins. Moreover, a hyaluronidase (LiHyal2) and an allergen (LALLT) from $L$. intermedia venom were recombinantly expressed and may be used to enhance the range of antigens for antivenom production (Justa et al., 2020; De-Bona et al., 2021).

Another strategy that has been explored is the production of monoclonal antibodies (mAbs) that cross-react with PLDs and neutralize toxic effects of Brown spider venoms. One of these mAbs, LimAb7, was initially produced by immunization with the venom of $L$. intermedia and efficiently neutralized the dermonecrotic activity of L. intermedia venom (Alvarenga et al., 2003). However, this mAb did not cross-react either with the venoms of $L$. gaucho or with the venoms of the Peruvian and Brazilian L. laeta (Alvarenga et al., 2003). LimAb7 was then re-engineered to a recombinant diabody, which was efficient in neutralizing the sphingomyelinase and hemolytic activities of $L$. intermedia venom, although it exhibited a limited stability in this dimeric configuration (Karim-Silva et al., 


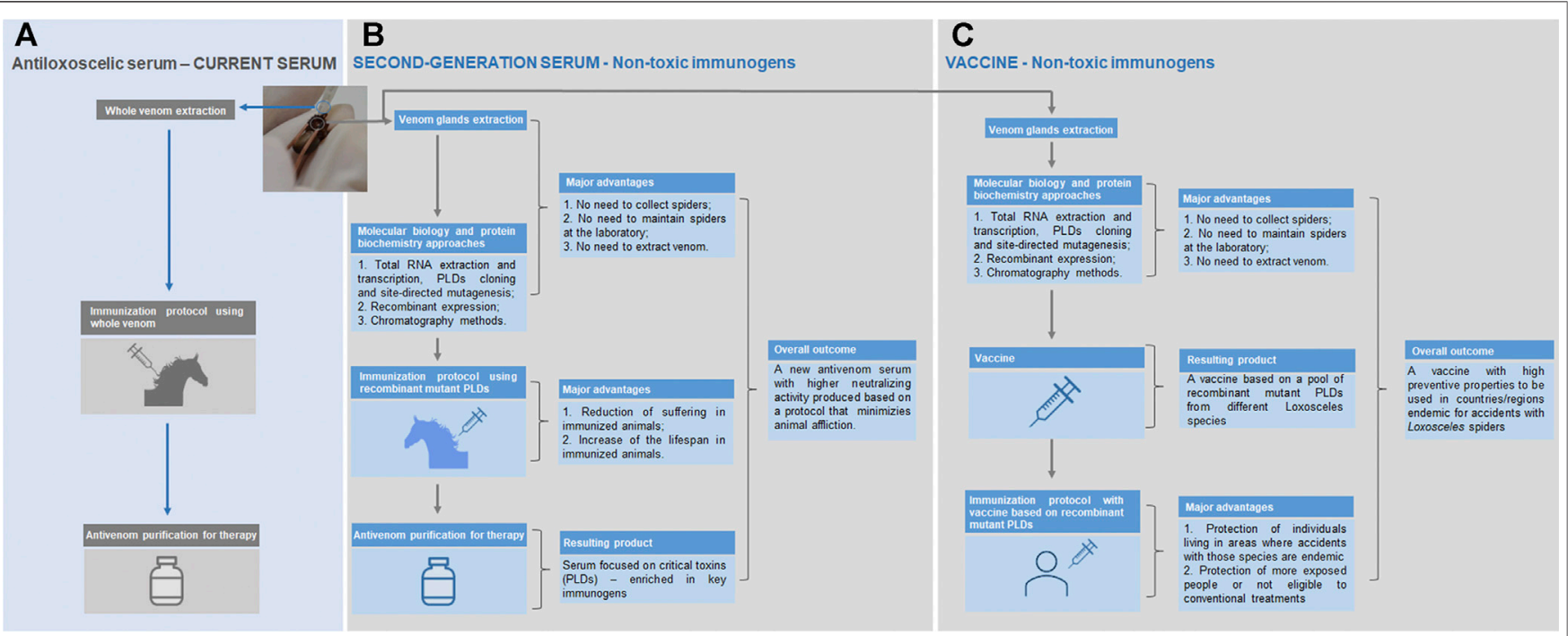

FIGURE 1 | Current antivenom therapy (antiloxoscelic serum) and the new approaches using non-toxic immunogens (second-generation serum and vaccine). (A) The current serum is produced using the whole venom extracted by a qualified staff from spiders captured in nature; the immunized animals to produce the serum develop unwanted reactions derived from the whole venom toxicity (pain and swelling at the inoculation site and, in some cases, suppuration; inappetence and episodes of mild and transient fever may appear); although the current protocol is well established, it is subjected to a certain irreproducibility, since the yield of venom extractions can vary and this could have a negative impact on the periodic animals' immunization procedures. (B) The strategy regarding the second-generation serum combines cost saving (no expenses related to spider collection missions and maintenance of these animals in captivity), staff safety (no recurrent manipulation of spiders) and easy management of the production process (it does not depend on the efficiency of the whole venom extraction); most importantly, the method for the generation of the new antivenom assures the depletion of adverse signs and symptoms in the immunized animals (mutant PLDs used are not tissue-destructive as the native PLDs) and the serum efficacy is expected to be higher, since it is produced using the molecules responsible for most of the noxious effects seen in the loxoscelism - the PLDs. (C) The development of a vaccine based in recombinant mutant PLDs from different Loxosceles species will be important for the protection of individuals living in areas where accidents with those species are endemic, as well as in people more exposed or not eligible to conventional treatments.

2016). Recently, humanized recombinant single-chain antibody fragments (scFvs) based on LimAb7 were produced and shown to inhibit the hemolytic effect of $L$. intermedia venom in the presence $(68 \%$ of inhibition) or absence $(>90 \%)$ of the complement system (Karim-Silva et al., 2020).

Aiming to overcome the limited cross-reaction of LimAb7 with different Loxosceles species, LiD1mAb16 was produced by immunization of mice with the PLD LiD1 (Dias-Lopes et al., 2014). In fact, this novel $\mathrm{mAb}$ recognized at least 25 proteins in each tested venom, i.e., L. intermedia, L. laeta and L. gaucho venoms, and interacts with an epitope inside the catalytic loop of LiD1. Pre-incubation of LiD1mAb16 with LiD1 protected the rabbits against dermonecrosis and local hemorrhage induced by the toxin with $80 \%$ of neutralization, while protection against edema achieved $48 \%$ of neutralization (Dias-Lopes et al., 2014). The chimeric protein rMEPlox mentioned earlier was also used as antigen to produce a monoclonal antibody named Lox-mAb3. This $\mathrm{mAb}$ recognized a metalloprotease of $L$. intermedia, crossreacted with metalloproteases of L. laeta and L. gaucho, and neutralized the fibrinogenolytic activity of $L$. intermedia venom, which may decrease hemorrhagic disturbances caused by Loxosceles envenomation (Costa et al., 2020).

Thus, as addressed, different strategies have been explored by toxinologists to acquire rationally designed tools to improve the management of patients bitten by brown spiders. The development of novel antivenoms based on recombinant toxins, chimeras or synthetic peptides are all promising approaches. Monoclonal antibodies and their derivatives are also tools with potential application to treat patients affected by loxoscelism.

\section{Vaccines to Prevent Loxoscelism}

Alternative strategies, such as vaccination protocols, have been studied to prevent loxoscelism. In this sense, various non-toxic immunogens based on Loxosceles PLDs were tested. For instance, some synthetic peptides similar to epitopes or antigenic regions of toxins were tested as immunogens in protection experiments. Linear and conformational epitopes from PLDs and chimeric proteins containing epitopes of different toxins were evaluated. Initially, rabbits immunized with a pool of non-toxic peptides corresponding to antigenic regions of $\mathrm{LiD} 1$ that produced a partially neutralizing serum (described in 2.1) was also tested for protection. When these animals were challenged with recombinant LiD1 (LiD1r), a protection of $40-50 \%$ was observed against dermonecrotic and hemorrhagic activities of this toxin, and $10 \%$ of protection was reached against the edematogenic effect (Felicori et al., 2009). In addition, a continuous B-cell epitope (27-mer peptide) corresponding to a region of $\mathrm{LiD} 1$ involved in the active site were synthesized and used as immunogen in mice and rabbits (Dias-Lopes et al., 2010). Immunized mice challenged with 1.5 LD50 of LiD1r presented $75 \%$ of protection against the lethal activity of this toxin. This immunization protocol in rabbits elicited about $70 \%$ of protection against dermonecrotic and hemorrhagic activities of LiD1r (1 MND/kg), and a low protection against edema (Dias-Lopes et al., 2010). Based on the findings regarding the epitope of LiD1 that 
TABLE 2 | Summarization of the protein content of Loxosceles spiders' venoms - classes of toxins and potential applications of these molecules to manage the loxoscelism and to develop drugs and biological/biotechnological inputs.

Brown spider venom molecules

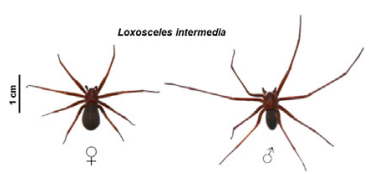

Potential applications and basic references on the matter
Phospholipases D (30-35 kDa)

Allergens $(42-45 \mathrm{kDa})$

Hyaluronidases (44-48 kDa)

Knottins (ICK peptides) (5-10 kDa)
- New therapies to treat loxoscelism

1. Development of a second generation antivenom produced from mutant PLDs or engineered peptides/chimeric proteins based on PLDs (Mendes et al. (2013), Vuitika et al. (2016), Lima et al. (2018), Calabria et al. (2019), da Silva et al. (2021))

2. Development of monoclonal antibodies that cross-react with venom PLDs (Alvarenga et al. (2003), Dias-Lopes et al. (2014), Karim-Silva et al. (2016), Costa et al. (2020))

3. Development of a vaccine for areas where the accidents are endemic (Lima et al. (2018), da Silva et al. (2021))

- Biotool to be used in studies regarding tumor cell biology (Wille et al. (2013), Siqueira et al. (2019))

- Antimicrobial drug (Segura-Ramírez and Silva Júnior. (2018))

- Development of anticoagulant drugs (Schemczssen-Graeff et al. (2021))

- Development of drugs for cancer treatment (Schemczssen-Graeff et al. (2021))

- As potential antibacterial (Costa et al. (2014)) and insecticide (Clemente et al. (2019)) molecules

- As tools for cell biology studies regarding proliferation, migration and control for protein half-life (Marathe et al. (2019))

- Development of skin and blood allergic sensitivity test (Linhart and Valenta. (2012))

- Therapeutic input to be used in desensitizing protocols to treat allergic patients (Linhart and Valenta. (2012))

- Biological inputs to be used in specific immunotherapy protocols (Linhart and Valenta. (2012))

- Drug diffusion enhancer (Weber et al. (2019))

- Development of drugs/inputs for cancer treatment (Khan et al. (2018))

- Development of inputs for aesthetic procedures (Weber et al. (2019))

- Development of effective bioinsecticides (Fitches et al. (2012), Bonning and Chougule. (2014), Herzig et al. (2016), Matsubara et al. (2017), King. (2019))

- Development of analgesic drugs (Cardoso et al. (2017), Dongol et al. (2019))

- Development of antifungal (Ayroza et al. (2012)), antiarrhythmic (Bode et al. (2001)) and antimalarial (Choi et al. (2004)) drugs

- Biological inputs to be used as imaging agents for tumor detection (Moore et al. (2013); Kintzing and Cochran. (2016))

$\operatorname{TCTP}(22 \mathrm{kDa})$ (Bhisutthibhan et al. (1998); Taylor et al. (2015))

- Development of drug delivery systems (Bae et al. (2018))

- Biotechnological input to be used as dental restorative material (Wanachottrakul et al. (2011), Sangsuwan et al. (2015), Kedjarune-Leggat et al. (2020))

is recognized by the monoclonal antibody LimAb7, two mimotopes were synthesized, entrapped into liposomes and used as immunogens in rabbits. These animals were challenged with $L$. intermedia venom, and immunization protocol showed $60 \%$ of protection against dermonecrosis, $80 \%$ against hemorrhage and $30 \%$ against edema (Moura et al., 2011). The aforementioned chimeric protein rMEPLox, containing epitopes from PLDs of $L$. laeta and L. intermedia, and from a metalloprotease and a hyaluronidase from $L$. intermedia, was also evaluated for its vaccinal potential. rMEPLox induced an immune response that completely blocked the dermonecrosis induced by $3.35 \mathrm{MND}$ of L. intermedia venom (Lima et al., 2018).

Non-toxic PLDs with a three-dimensional structure similar to active isoforms were also tested as immunogens, following the notion that most epitopes in proteins are discontinuous and do not react peptide fragments from the parent protein (Van Regenmortel, 1996). For example, the aforementioned nontoxic PLD fused with $\beta$-galactosidase (Li-rec) were used in a vaccination protocol in mice, and fully protected the animals against the lethal effects of $2.5 \mathrm{LD} 50$ of $L$. intermedia venom. The same study also showed that rabbits immunized with Li-rec were partially protected against dermonecrosis 120 days after the last immunization dose, indicating that this protein generates long lasting antibodies (Araujo et al., 2003). The inactive PLD isoform
rLIPLD2 from L. laeta were also evaluated for this purpose. The protection of rabbits against the dermonecrotic activity of L. laeta venom was evaluated in animals previously vaccinated with rLIPLD2, and a good protection was observed (Catalán et al., 2011). These studies support the use of non-toxic recombinant proteins in vaccination protocols against loxoscelism. In this sense, the mutated and inactive recombinant PLDs of $L$. intermedia, L. laeta and L. gaucho mentioned above could be used as antigens in a new-generation vaccination protocol in areas where accidents with those species are endemic, as well as in people more exposed or not eligible to conventional treatments, as depicted in Figure 1 (Vuitika et al., 2016; da Silva et al., 2021).

\section{VENOM PEPTIDES AND PROTEINS AS POTENTIAL NOVEL DRUGS}

Brown spider venoms are complex chemical cocktails with proteins and peptides with quite specific biochemical and biological activities. Such activities can be further explored to apply these toxins as therapeutic or biological agents optimized for numerous purposes (summarized in Table 2). In the next items, such potential applications will be explored, based on the known biological activities of these toxins and on the literature regarding these proteins. 


\section{Serine Protease Inhibitors: Candidates in the Development of Biochemical Reagents, Insecticides, Antibacterial and Antitumoral Drugs}

Serine protease inhibitors have been described in the literature as molecules with many functional activities regarding both physiological and pathological processes, not to mention the vast potential for biotechnological exploitation (Gettins, 2002; Huntington, 2011; Lucas et al., 2018). Although little studied, serine protease inhibitors in the venoms of Loxosceles spiders have been reported in different species, which shows the biological conservation and the importance of this components in the venoms. The first finding indicating the existence of serine protease inhibitors in Loxosceles venoms was reported in a study using the venom of $L$. reclusa (North America), in which the presence of a complement inhibitor was identified after venom fractionation using Sephadex G-75 exclusion chromatography (Kniker et al., 1969). Later, other more specific and directed studies identified these inhibitors in different species endemic in Brazil and South America. Omics methods have reported the presence of serine protease inhibitors in the venoms of L. laeta (Fernandes-Pedrosa et al., 2008), L. intermedia (Dos Santos et al., 2009; Gremski et al., 2010) and, more recently, in L. gaucho venom (Calabria et al., 2019), always as low expressed proteins. However, the presence of serine protease inhibitors in the venoms of different species of Loxosceles spiders is not sufficient to prove that these molecules are in fact toxins and have harmful activities with clinical correlation to the envenoming. In this context, the inhibitory activity of plasma coagulation induced by thrombin was associated with a recombinant serpin of $L$. intermedia (Schemczssen-Graeff et al., 2021), which could suggest that these venom molecules may contribute with the delay of plasmatic coagulation caused by Loxosceles venom (Zanetti et al., 2002) and, consequently, increasing the hemorrhagic disturbances during loxoscelism, such as local hemorrhage observed in the cutaneous lesion (Ospedal et al., 2002). As venom components, serine protease inhibitors may also act, for instance, as protectors, preventing the proteolysis of selfproteins/toxins and then increasing the half-life of them; this contributes to the integrity of the venom, keeping its potentiality in order to be used during hunting preys, defense against predators or in accidents with humans (Dos Santos et al., 2009; Gremski et al., 2010).

The great advance regarding studies of serine protease inhibitors found in Loxosceles venoms emerged with the cloning and recombinant expression of serine protease inhibitor from $L$. intermedia in Spodoptera frugiperda cells using baculovirus technology. This molecule was called LSPILT, from Loxosceles Serine Protease Inhibitor-Like Toxin (Schemczssen-Graeff et al., 2021). Authors have shown that this protein has a molecular mass of $46 \mathrm{kDa}$, and the amino acid sequence shows the presence of the signature for the Serpin super family members. LSPILT is homologous to other serpins found in spiders of other genus, as well as in other arthropods. In addition, the immunoassays suggested the conservation of this class of molecules in Loxosceles gaucho, L. laeta and L. intermedia venoms
(Schemczssen-Graeff et al., 2021). The expression and purification of LSPILT yielded $8.0 \mathrm{mg} / \mathrm{L}$ of culture supernatant in its soluble form and without requiring refolding. LSPILT inhibits the activity of trypsin upon gelatin and vitronectin in vitro. LSPILT activity was also demonstrated by its inhibitory activity on the plasma coagulation induced by thrombin, inhibitory effect of lysis of $T$. cruzi trypomastigotes dependent on convertases (serino proteases) of complement system. Finally, LSPILT induced the inhibition of melanoma cell (B16-F10) proliferation and migration, events with great participation of serine proteases. These results all together has proven that LSPILT is a molecule with a broad spectrum of inhibitory activity on serine proteases (Schemczssen-Graeff et al., 2021).

These molecules are versatile and are efficient tools, which can be used to understand the participation of serine protease inhibitors in the context of envenoming or as endogenous proteolytic inhibitor of venom components. Also, LSPILT constitutes a tool to study structural aspects of serpin-family members through crystallography methods. LSPILT can be used as a prototype (taking into account the participation of serpins in a large number of biological events and in human health) for analyzes concerning biotechnological applicabilities, as previously pointed for other serpin family-members (Gaci et al., 2013). Regarding cell biology experimental studies, the recombinant LSPILT can be used as a prototype in protocols aiming to unveil how cells proliferate, migrate, undergo to apoptosis and control cellular protein half-life (Marathe et al., 2019). Regarding the control of agricultural infestations, LSPILT can be investigated as a potential input, since serpins have been shown as molecules able to inhibit digestive enzymes present in the gastrointestinal tract of insect, inducing an insecticide effect (Clemente et al., 2019). It has already been reported that serine protease inhibitors can exhibit antibacterial activities, which makes them potential antibacterial agents in the treatment of human diseases (Costa et al., 2014). Finally, LSPILT can be used as an useful reagent in different biochemical experimental protocols, such as serine protease ligands in affinity chromatography procedures, in the purification of proteases, or as an inhibitory agent during cell analysis or protein purification, avoiding undesirable proteolytic effects (Sabotič and Kos, 2012).

\section{Allergens: Potential Compounds to be Applied in the Diagnose and Treatment of Allergic Events}

As mentioned above, the most common complications described in accidents caused by Loxosceles spiders are inflammatory reactions at the bite site, which can evolve to dermonecrosis between 24 and $48 \mathrm{~h}$ after accidents (Isbister and Fan, 2011; Malaque et al., 2011; Gremski et al., 2014; Chaves-Moreira et al., 2017). Signs of allergenic responses are also reported, and are characterized by swelling, itching, redness and cutaneous rash. These allergenic manifestations are not restricted to the bite site and usually emerge earlier when compared to inflammatory signs, and they clearly indicate the presence of allergenic 
toxins in the venoms (Makris et al., 2009; Isbister and Fan, 2011; Lane et al., 2011; Malaque et al., 2011; Justa et al., 2020). The presence of toxins theoretically responsible for allergic responses in the Loxosceles venoms was initially identified in the analysis of the transcriptome of $L$. laeta venom glands (Fernandes-Pedrosa et al., 2008). Subsequently, a proteomic study of the venom of $L$. intermedia, revealed the presence of a molecule with high identity to a protein similar to an allergen found in mites (Mite Allergen of Group 7) (Dos Santos et al., 2009), which was later confirmed by the analysis of $L$. intermedia venom gland transcriptome (Gremski et al., 2010). The study of the transcriptome of $L$. gaucho venom glands also reported transcripts related to allergens (Calabria et al., 2019).

The confirmation of toxins as allergens in the venoms of different Loxosceles species has finally been described by the cloning and recombinant expression of a toxin from $L$. intermedia (Justa et al., 2020). The authors showed the presence of an allergen belonging to the CAP superfamily (Cysteine-Rich Secretory Proteins) with $42 \mathrm{kDa}$. This toxin was named LALLT (Loxosceles Allergen-Like Toxin), and it was produced by using a eukaryotic heterologous expression system (Sf9 insect cells combined to the baculovirus technology) (Justa et al., 2020). Research on amino acid alignments with other allergens, immunological reactivity using antibodies raised originally to LALLT or crude venoms from different Loxosceles species, and searches for high identity mRNAs sequences in other Loxosceles species showed that LALLT has biological conservation (Justa et al., 2020). Recombinant LALLT was able to trigger mast cells degranulation, in addition to cause leukocyte infiltration into the dermis of rabbits, induce paw edema and increase the vascular permeability in mice skin (Justa et al., 2020). Together, the experimental data acquired state this toxin as an allergic agent with clinical potential, which should be evaluated as a target in the treatment of loxoscelism, especially in injured patients with a history of previous allergies to arthropods.

As protein content in Loxosceles venoms is quite reduced (Sams et al., 2001; Binford and Wells, 2003; Da Silva et al., 2004; Senff-Ribeiro et al., 2008; Gremski et al., 2014), the production of recombinant LALLT in a eukaryotic model is a breakthrough regarding the characterization of toxins from Loxosceles spiders. It was the first recombinant Loxosceles toxin to be successfully produced in the mentioned model. The availability of correctfolded and functional isoforms of LALLTs will allow, in a near future, the crystallization of this toxin, providing data related to the structure/function relationship and the action mechanism of this molecule. In addition, with a functional eukaryotic recombinant model, we can exhaust the analysis of biochemical, biological, immunological and pharmaceutical activities for members of this family. Questions regarding the real allergenic potential of these toxins, other toxic activities that have not yet been described and cell receptors involved with the toxic activities can be answered using recombinant allergens produced according to the mentioned methodology.

The availability of the recombinant LALLT may enable its use as antigen for skin allergic sensitivity test, allowing the identification of sensitive populations and more rational treatments, reducing adverse reactions due to envenoming. They may also be used as antigens for blood allergic tests, seeking for reactivity with immunoglobulins present in the blood of patients and confirming a predisposition to allergies. In severe cases, recombinant LALLT may also be used in desensitizing protocols to treat allergic patients. Finally, recombinant LALLT can be used in specific immunotherapy protocols for related antigens, giving rise to protective vaccines against severe allergic attacks, as previously discussed for other allergenic factors (Linhart and Valenta, 2012).

\section{Hyaluronidases: Adjuvants to Enhance the Diffusion of Other Drugs and Agents to Correct Esthetic Filling Procedures}

Together with mammalian hyaluronidases, venom hyaluronidases belong to the EC 3.2.1.35 group of enzymes and act as endo- $\beta$ - $N$-acetyl-D-hexosaminidases. Their main substrate is hyaluronic acid (HA), but can also cleave chondroitin sulfate (Bordon et al., 2015). HA is abundant in the extracellular matrix (ECM) of mammal soft connective tissues (Girish and Kemparaju, 2007). Besides its structural basic functions in ECM, HA has been linked to more specific molecular functions, such as binding to ECM proteins and to particular cell receptors that mediate important physiological processes (Girish and Kemparaju, 2007).

Degradation of HA by hyaluronidase increases connective tissue permeability and decreases viscosity of body fluids. These enzymes are directly involved in the spread of venoms and toxins, and in important processes such as fertilization and cancer progression. Depolymerization of HA also impairs the ECM activity as a reservoir of growth factors (Cramer et al., 1994; Menzel and Farr, 1998; Kemparaju and Girish, 2006; Chao et al., 2007). Hyaluronidases have been described in several animal venoms like snakes, bees, scorpions, spiders, lizards and stingrays (Kemparaju and Girish, 2006; Magalhães et al., 2008; Ferrer et al., 2013). Hyaluronidases from venomous animals are commonly described as spreading factors once HA degradation increases the ECM permeability, rendering tissues highly permeable to the toxic components of venom (Girish and Kemparaju, 2007).

Multiple applications regarding mammalian hyaluronidases have already been described, one of which is related to the combined use with local anesthetics to enhance the diffusion of injected therapeutic drugs. On this subject, the application of a recombinant human hyaluronidase $(\mathrm{rHuPH} 20)$ has recently gained prominence for the subcutaneous application of insulin, morphine, immunoglobulins and other pharmaceuticals (Weber et al., 2019). In different studies, it has been demonstrated that the administration of hyaluronidases with anti-cancerous drugs reduces the interstitial fluid pressure within the tumorous tissue and, as a spreading factor, these enzymes can also be used to enhance the penetration of oncolytic agents, potentiating the effectiveness of the therapy. The additive use of the hyaluronidases is not limited to the chemotherapy as they may also be used in combination with radioimmunotherapy (Khan et al., 2018). Furthermore, studies have shown the effectiveness of hyaluronidase as an 
adjuvant in neuroplastic procedures by reducing pain rating compared to other techniques (Helm and Racz, 2019). The injection of hyaluronidase is also used to correct unaesthetic overcorrections and to reverse chronic edema or vascular occlusion after HA-filler applications (Weber et al., 2019).

Nowadays, commercial formulations of exogenous hyaluronidases include purified forms from bovine (BTH) and ovine testicles $(\mathrm{OTH})$ and recombinant human hyaluronidase (rHuPH20) (Searle et al., 2020). Animal derived hyaluronidases are extracted from testis tissue, and are generally purified by series of multiple precipitation, fractionation and filtration steps (Farooqui and Srivastava, 1979; Lyon and Phelps, 1981; Kaya et al., 2015). One of the limitations of these methods is that these extracts are often contaminated with proteases, immunoglobulin, and other elements, which can increase capillary permeability or IgE-mediated hypersensitivity reactions (Silverstein et al., 2012). The recombinant form of hyaluronidase is clinically available as Hylenex $^{\mathrm{TM}}$ (Baxter, Deerfield, IL). The recombinant human hyaluronidase $(\mathrm{rHuPH} 20)$ is a highly purified protein. The production uses Chinese hamster ovary cells $(\mathrm{CHO})$ to express the human recombinant genetic engineered enzyme. This hyaluronidase is purified through a series of column chromatographies and other processing steps, generating a protein with less impurities and potential pathogens, reducing the risk of hypersensitivity reactions (Frost, 2007; Silverstein et al., 2012).

Venom hyaluronidases have been studied as purified enzymes (Poh et al., 1992; Girish et al., 2004; Morey et al., 2006; Horta et al., 2014) or as recombinant proteins mainly expressed in insect cells (Soldatova et al., 2007; Clement et al., 2012; De-Bona et al., 2021). In Loxosceles spider venoms, hyaluronidase activity was identified in six Loxosceles species (L. rufescens, L. deserta, L. gaucho, L. intermedia, L. laeta and L. reclusa) and some of these results were confirmed by subsequent proteome and transcriptome studies that described hyaluronidases or coding sequences for such enzymes in various Loxosceles venoms (Young and Pincus, 2001; Barbaro et al., 2005; Fernandes-Pedrosa et al., 2008; Dos Santos et al., 2009; Gremski et al., 2010; Trevisan-Silva et al., 2017; Siqueira et al., 2019). Initially, a recombinant hyaluronidase from L. intermedia venom was produced in a prokaryotic model, purified, refolded and characterized. LiHyal, as it was named, was able to degrade hyaluronic acid and chondroitin sulfate in vitro, and biological assays revealed that this recombinant toxin was able to increase erythema, ecchymosis and dermonecrotic effects when associated with a recombinant phospholipase $\mathrm{D}$, indicating that this protein acts as spreading factor (Ferrer et al., 2013). Later, a similar isoform was expressed in baculovirus-infected insect cells as a soluble and active recombinant hyaluronidase, named LiHyal2, with similar in vitro and in vivo activities than LiHyal (De-Bona et al., 2021). As it was produced by eukaryotic cells, LiHyal2 is posttranslationally modified by the addition of high-mannose $\mathrm{N}$-linked carbohydrates.

In fact, other venom hyaluronidases, such as those from Apis mellifera (honeybee) and Brachypelma vagans (tarantula), were efficiently expressed in baculovirus systems in insect cells (Soldatova et al., 2007; Clement et al., 2012). This expression system has proved to be quite efficient in producing posttranslationally modified and active venom hyaluronidases and may be an interesting alternative to purified or recombinant mammal hyaluronidases. In addition, as venom hyaluronidases belong to the same group of enzymes as mammal hyaluronidases, which have already been used as therapeutic agents, they emerge as an alternative source of such remarkable molecules.

\section{Knottins (Inhibitory Cystine Knot Peptides): Potential Peptides to be Used in the Development of Bioinsectices, Analgesics and Tumor Imaging Agents}

Knottins, also known as ICK peptides (Inhibitory Cystine Knot), constitute a family of peptides that characteristically contain cysteine residues forming intramolecular disulfide bonds. These disulfide bonds are arranged to set a pseudo-knot structure, in which a ring established by two disulfide bonds connected to the peptide backbone is intersected by a third disulfide bond (Norton and Pallaghy, 1998; Saez et al., 2010). Knottins have already been identified as components of Loxosceles spiders' venoms through biochemical and molecular biology studies (De Castro et al., 2004; Gremski et al., 2010; Matsubara et al., 2013, 2017; Meissner et al., 2016). Their biological function as venom toxins has been proven to be insecticide, by displaying toxic effects in insects for feeding purpose. Two experimental studies regarding knottins from $L$. intermedia have demonstrated this insecticide activity. First, De Castro et al. (2004), through chromatography approaches, purified a fraction containing three native knottins (identified as LiTx1, LiTx2 and LiTx3) that induced lethal flaccid paralysis on larvae of Spodoptera frugiperda (fall armyworm). Additionally, Matsubara et al. (2017) produced a recombinant knottin $\left(\mathrm{U}_{2^{-}}\right.$ SCRTX-Lilb) that exhibited long-lasting paralysis in sheep blowflies (Lucilia cuprina), which was irreversible even at $72 \mathrm{~h}$ post-injection. These exploratory findings unveil the high potential of knottins to be used in the development of bioinsecticides, which constitute an environmentally healthier approach to control pests of economic interest when compared to the chemical pesticides widely used (Windley et al., 2012; King, 2019). Studies regarding knottins from spiders' venoms have shown that these peptides can be highly selective, being even taxaspecific in some cases (Herzig et al., 2016; King, 2019). This feature makes knottins desirable tools to manage crop pests, since these molecules do not represent harm to insects or other nontarget organisms beneficial to the ecosystem (Nakasu et al., 2014). Moreover, it has been described that knottins are, in general, orally active, which means that these toxins are ingested by the insects and are absorbed in the midgut. Some knottins have been engineered in order to be produced as recombinant fusion proteins to molecules (such as lectins) that enhance the absorption by insect's midgut epithelium (Fitches et al., 2004, 2012; Bonning and Chougule, 2014). Then, these peptides get into the hemolymph and reach their targets, which are ion channels and receptors present in neuromuscular junctions or neurons located in the central nervous system (King, 2019). Due to their "knot" structure, knottins are highly protease-resistant and have 
been proven to greatly maintain their stability in samples of insect hemolymph (Herzig and King, 2015). In addition to all the already mentioned advantages, spider knottins exert their neurotoxic effects on insects in a fast-manner and are not predicted to bioaccumulate or generate products toxic to the environment after being degraded (King, 2019).

Experimental evidence regarding other applications of knottins from Loxosceles spiders remains lacking. However, it is relevant to highlight that $L$. intermedia knottins, for example, have proven to be the most abundant in terms both of transcripts encoded in the venom glands and protein content (together with the phospholipases D) in venom samples analyzed using SDSPAGE (Gremski et al., 2010; Matsubara et al., 2017). Also, the diversity of these peptides has shown to be even greater as demonstrated by the existence of different knottins encoded in the venom glands of three different Loxosceles species (Matsubara et al., 2017). This great representativeness is a strong indication of the existence of multiple targets and, consequently, of multiple applications for these toxins. Thus, another search for the use of knottins from Loxosceles is related to their possible analgesic properties, which are suggested by the painless characteristic of the bites in humans (Da Silva et al., 2004; Gremski et al., 2014). Studies regarding knottins from several spiders' species have shown that these toxins can modulate specific ion channels and receptors associated to the pathophysiological event of pain, inducing analgesic effects. For example, it was shown that two synthetic forms of the knottin peptide $\mu$-TRTX-Dfla (Dfla) from a tarantula (D. fasciatus) interacts with a specific region of a voltage-gated sodium channel $\left(\mathrm{Na}_{\mathrm{v}} 1.7\right)$, which is known to be activated during the pain event in humans and induces analgesia in mice previously treated with a scorpion molecule (OD1) that potentiates the activity of $\mathrm{Na}_{V} 1.7$ channels (Cardoso et al., 2017; Dongol et al., 2019).

Knottins from spider venoms have also been associated to antifungal (Ayroza et al., 2012), antiarrhythmic (Bode et al., 2001) and antimalarial (Choi et al., 2004) properties. Other spiders' knottins have been engineered to be used as imaging agents, by producing molecules containing peptide fragments that bind to tumor cells and fluorescent probes; the knottins have been thought to be used in this approach because they are extremely biological- and thermostable in body fluids, exhibit high affinity to their target in minute concentrations, as well as display rapid clearance from non-target tissues/organs, which means that they are efficiently eliminated by the kidneys (Moore et al., 2013; Kintzing and Cochran, 2016). As described, given the diversity of knottins found in the venoms of Loxosceles spiders and their respective targets, multiple activities such as those herein mentioned can be investigated in order to determine new uses for these toxins.

\section{Translationally Controlled Tumor Protein: Target Candidates in Histamine-Related Pathologies and as Pro-Proliferative Biomaterial}

A protein from the translationally controlled tumor protein (TCTP) family was described in Loxosceles venoms (Sade et al., 2012). The TCTP protein, also known as histaminereleasing factor (HRF) or fortilin, is a highly conserved and ubiquitous protein, described as multifunctional due to its wide range of function repertoire regarding both intracellular and extracellular biological processes (Bommer and Telerman, 2020). Loxosceles TCTP was initially described in L. intermedia transcriptome (Gremski et al., 2010). TCTP family proteins have already been described in other arthropods such as in the gland secretion of ixodid ticks (Mulenga and Azad, 2005), in the venom gland of tarantula Grammostola rosea (Kimura et al., 2012), and in the venom gland transcriptomic and proteomic analyses of Scytodes spiders (Zobel-Thropp et al., 2014).

The recombinant $L$. intermedia TCTP (LiRecTCTP) produced in a prokaryotic heterologous system causes edema and increases vascular permeability in vivo and in animal models (Sade et al., 2012). This protein was related to the inflammatory activity of the venom of L. intermedia. Later, TCTP was also found in L. laeta transcriptome study, and its presence in L. gaucho venom was inferred by immunological cross-reaction studies (Buch et al., 2015). TCTP protein was immunodetected in the whole venom of Loxosceles species (L. intermedia, L. gaucho, and L. laeta) as well as described in the proteomic study of $L$. intermedia venom (Trevisan-Silva et al., 2017). Recently, we have shown that LiRecTCTP acts as a synergistic factor for the PLD actions (LiRecDT1), highlighting its contribution to the pathophysiology of Loxoscelism (Boia-ferreira et al., 2019).

Loxosceles TCTP contribution to the exacerbated inflammatory response observed in envenomated patients is related to its histaminergic properties, which suggests that the inhibition of LiTCTP mast cell activation effects could be a therapeutic approach to reduce the inflammatory events responsible for the main symptoms in cutaneous loxoscelism. TCTP was already reported in the biological fluid of asthmatic and parasitized patients (MacDonald, 2012) and human TCTP (54.9\% of similarity with LiRecTCTP, using EMBOSS Needle tool) was described as a target for asthma and allergy clinical treatments (Kawakami et al., 2019).

Regarding the multifunctional role of TCTP, LiTCTP is a promising toxin and potential target model in the several cellular processes in which TCTP protein participates (Amson et al., 2013). As TCTP family is highly conserved, we can suggest to LiTCTP some biotechnological applications that have already been described for other TCTP proteins, in the different fields of general biology (toxinology, allergy, parasitology, and oncology) and biomaterial research (dental restoration and drug delivery) as it is discussed hereafter.

In parasitology, TCTP is suggested to be involved in the establishment, maintenance, and pathogenesis of parasite infections. When the Plasmodium TCTP (42.2\% of similarity with LiRecTCTP) was evaluated as a malaria vaccine, a significant reduction of parasitemia in the early stages of the infection was seen (Taylor et al., 2015). Plasmodium TCTP has been shown to bind directly the anti-malarial drug artemisinin (Fujita et al., 2008) and to have higher expression levels on increased drug resistance conditions (Bhisutthibhan et al., 1998).

TCTP proteins harbor, in their N-terminal, a transduction domain (PTD) which could be applied as vehicles in drug delivery 
systems. These domains are recognized as promising vehicles for the delivery of macromolecular drugs. Different studies showed the effectiveness of the TCTP carrier peptide (residues 1-10, MIIYRDLISH) internalization in different cell types (Bae and Lee, 2013; Maeng et al., 2013; Calderón-Pérez et al., 2014). A modified version of TCTP PTD was shown as a promising vehicle for intranasal delivery of insulin (Bae et al., 2018). More recently, TCTP was shown to translocate into oocytes across the zona pellucida $(\mathrm{ZP})$ and to prevent quality deterioration during in vitro culture. This data is quite important as the delivery of exogenous molecules into mammalian oocytes or embryos has been a challenge because of the existence of the protective $\mathrm{ZP}$ surrounding the oocyte membrane (Jeon et al., 2017).

TCTP proteins present proliferative properties and antiapoptotic activity, and TCTP from Fenneropenaeus merguiensis (banana prawn) was explored as supplements in dental restorative materials (Wanachottrakul et al., 2011). This TCTP was shown to promote osteoblast cells proliferation, differentiation and function, highlighting its potential use as a supplementary medical material in dentistry (Sangsuwan et al., 2015; Kedjarune-Leggat et al., 2020). TCTP ability to protect cells in a range of stress conditions was recently described in cardiomyocytes (Cai et al., 2019). Results have shown that TCTP plays a critical role for the survival of these cells and has a protective function against drug-induced cardiac dysfunction in mice.

TCTP's collection of molecular partners and involvement in different biological events is behind this protein's biotechnological potential, which exploration has just initiated.

\section{Phospholipases D: Candidates in the Development of Antibacterial Drugs and Tools to Comprehend the Regulation of Some Biological Processes}

Phospholipases D are enzymes that have a broad range of biological activities and are involved in the regulation of many pathological processes including those related to tumor cells (Houben and Moolenaar, 2011). The protein Autotaxin (ATX), for example, is a phospholipase D with activity on lysophosphatidylcholine and it is responsible for the formation of lysophosphatidic acid (LPA) in the blood and other tissues. ATX is highly expressed in several tumors, and the lipid mediator released (LPA) evokes responses such as cell migration and proliferation, as well as and survival for a wide range of tumor cells (Tania et al., 2010; Houben and Moolenaar, 2011). The $L$. intermedia PLD, LiRecDT1 can trigger some biological responses on melanoma cells, such as proliferation and calcium influx, besides binding to the membrane of B16F10 cells (Wille et al., 2013). A study that investigated the activity of the L. gaucho PLD LgRec1 on B16F10 cells showed that this toxin reduces the viability of those cells, thus presenting a potential antitumor activity (Siqueira et al., 2019). The authors potentialized this activity by fusing this $\operatorname{LgRec1}$ with a snake venom disintegrin called Echistatin. The resulting hybrid protein, named Rechistatin, was more efficient to promote cell death than only
Echistatin or only LgRec1 since the disintegrin portion helped to deliver the PLD to the target cell (Siqueira et al., 2019). A deeper investigation regarding this activity of Loxosceles PLDs still remains to be done. In addition, as ATX, LiRecDT1 can be a potential exogenous tool to better understand the regulation of biological processes in tumor cells and in cell membranes.

Besides the potential use of Loxosceles PLDs to study tumor cells and their activities, other fields to apply these toxins as useful components have been explored. Currently, the resistance of some bacteria to antibiotics is a major problem to the health care systems. Thus, the development of new drugs with antibacterial activity has become an emerging area (Echols, 2012; Sudarshan and Dhananjaya, 2016). Peptides present in venoms of animals such as scorpions, snakes and spiders are potential sources of such molecules (Siqueira et al., 2019). In this sense, Loxosceles venoms' PLDs may also serve as potential antimicrobial drugs. A peptide from the venom of L. gaucho (U1-SCRTX-Lg1a) showed antibacterial activity in gramnegative bacteria, such as Pseudomonas aeruginosa and Enterobacter cloacae, and did not affect the viability of HeLa cells. There is evidence that these peptides arise from a limited proteolytic cleavage of PLDs, since it shows great similarity with some regions of the amino acid sequences of nine Loxosceles PLDs (Segura-Ramírez and Silva Júnior, 2018).

\section{PERSPECTIVES}

Brown spider venom presents a range of natural proteins and peptides that could eventually find their way into pharmaceuticals, biological agents and tools for the development of novel therapies. The potential applications of such molecules and the search for novel therapies to treat loxoscelism will continue to stimulate the studies regarding this complex venom, which will certainly result in novel approaches to overcome various challenges in a foreseeable future.

\section{AUTHOR CONTRIBUTIONS}

Conceptualization, LG, SV; resources, LG, JM, SV; writing-original draft preparation, LG., FM, NP, BA, PS, HJ, AW, AS-R, and SV; writing-review and editing, LG, FM, SV; supervision, LG. All authors have read and agreed to the published version of the manuscript.

\section{FUNDING}

This work was supported by grants from Secretarias de Estado de Ciência, Tecnologia e Ensino Superior (SETI) e de Saúde (SESA) do Paraná, Fundação Araucária-PR, MS-Decit/PPSUS (057/ 2017), Universidade Federal do Paraná (04/2018; 04/2019), CNPq (408633/2018-2; 303868/2016-3) and CAPES, Brazil. 


\section{REFERENCES}

Abraham, M., Tilzer, L., Hoehn, K. S., and Thornton, S. L. (2015). Therapeutic Plasma Exchange for Refractory Hemolysis after Brown Recluse Spider (Loxosceles Reclusa) Envenomation. J. Med. Toxicol. 11, 364-367. doi:10.1007/s13181-015-0485-9

Alvarenga, L. M., Martins, M. S., Moura, J. F., Kalapothakis, E., Oliveira, J. C., Mangili, O. C., et al. (2003). Production of Monoclonal Antibodies Capable of Neutralizing Dermonecrotic Activity of Loxosceles Intermedia Spider Venom and Their Use in a Specific Immunometric Assay. Toxicon 42, 725-731. doi:10.1016/j.toxicon.2003.09.006

Amson, R., Pece, S., Marine, J.-C., Fiore, P. P. D., and Telerman, A. (2013). TPT1/ TCTP-Regulated Pathways in Phenotypic Reprogramming. Trends Cel Biol. 23, 37-46. doi:10.1016/j.tcb.2012.10.002

Araujo, S. C., Castanheira, P., Alvarenga, L. M., Mangili, O. C., Kalapothakis, E., and Chávez-Olórtegui, C. (2003). Protection against Dermonecrotic and Lethal Activities of Loxosceles Intermedia Spider Venom by Immunization with a Fused Recombinant Protein. Toxicon 41, 261-267. doi:10.1016/S0041-0101(02) 00282-9

Ayroza, G., Ferreira, I. L. C., Sayegh, R. S. R., Tashima, A. K., and da Silva Junior, P. I. (2012). Juruin: An Antifungal Peptide from the Venom of the Amazonian Pink Toe Spider, Avicularia Juruensis, Which Contains the Inhibitory Cystine Knot Motif. Front. Microbio. 3, 1-10. doi:10.3389/fmicb.2012.00324

Bae, H.-D., Lee, J., Jun, K.-Y., Kwon, Y., and Lee, K. (2018). Modification of Translationally Controlled Tumor Protein-Derived Protein Transduction Domain for Improved Intranasal Delivery of Insulin. Drug Deliv. 25, 1025-1032. doi:10.1080/10717544.2018.1464081

Bae, H.-d., and Lee, K. (2013). On Employing a Translationally Controlled Tumor Protein-Derived Protein Transduction Domain Analog for Transmucosal Delivery of Drugs. J. Controlled Release 170, 358-364. doi:10.1016/ j.jconrel.2013.06.010

Barbaro, K. C., Ferreira, M. L., Cardoso, D. F., Eickstedt, V. R., and Mota, I. (1996). Identification and Neutralization of Biological Activities in the Venoms of Loxosceles Spiders. Braz. J. Med. Biol. Res. 29, 1491-1497.

Barbaro, K. C., Knysak, I., Martins, R., Hogan, C., and Winkel, K. (2005). Enzymatic Characterization, Antigenic Cross-Reactivity and Neutralization of Dermonecrotic Activity of Five Loxosceles Spider Venoms of Medical Importance in the Americas. Toxicon 45, 489-499. doi:10.1016/ j.toxicon.2004.12.009

Beilman, G. J., Winslow, C. L., and Teslow, T. W. (1994). Experimental Brown Spider Bite in the guinea Pig: Results of Treatment with Dapsone or Hyperbaric Oxygen. J. Wilderness Med. 5, 287-294. doi:10.1580/0953-9859-5.3.287

Bermúdez-Méndez, E., Fuglsang-Madsen, A., Føns, S., Lomonte, B., Gutiérrez, J., and Laustsen, A. (2018). Innovative Immunization Strategies for Antivenom Development. Toxins 10, 452. doi:10.3390/toxins10110452

Bhisutthibhan, J., Pan, X.-Q., Hossler, P. A., Walker, D. J., Yowell, C. A., Carlton, J., et al. (1998). The Plasmodium Falciparum Translationally Controlled Tumor Protein Homolog and its Reaction with the Antimalarial Drug Artemisinin. J. Biol. Chem. 273, 16192-16198. doi:10.1074/jbc.273.26.16192

Binford, G. J., and Wells, M. A. (2003). The Phylogenetic Distribution of Sphingomyelinase D Activity in Venoms of Haplogyne Spiders. Comp. Biochem. Physiol. B: Biochem. Mol. Biol. 135, 25-33. doi:10.1016/S10964959(03)00045-9

Bode, F., Sachs, F., and Franz, M. R. (2001). Tarantula Peptide Inhibits Atrial Fibrillation. Nature 409, 35-36. doi:10.1038/35051165

Boia-Ferreira, M., Moreno, K. G., Basílio, A. B. C., da Silva, L. P., Vuitika, L., Soley, B., et al. (2019). TCTP from Loxosceles Intermedia (Brown Spider) Venom Contributes to the Allergic and Inflammatory Response of Cutaneous Loxoscelism. Cells 8, 1489. doi:10.3390/cells8121489

Bommer, U.-A., and Telerman, A. (2020). Dysregulation of TCTP in Biological Processes and Diseases. Cells 9, 1632. doi:10.3390/cells9071632

Bonning, B. C., and Chougule, N. P. (2014). Delivery of Intrahemocoelic Peptides for Insect Pest Management. Trends Biotechnol. 32, 91-98. doi:10.1016/ j.tibtech.2013.08.001

Bordon, K. C. F., Wiezel, G. A., Amorim, F. G., and Arantes, E. C. (2015). Arthropod Venom Hyaluronidases: Biochemical Properties and Potential
Applications in Medicine and Biotechnology. J. Venom. Anim. Toxins Incl. Trop. Dis. 21, 1-12. doi:10.1186/s40409-015-0042-7

Buch, D. R., Souza, F. N., Meissner, G. O., Morgon, A. M., Gremski, L. H., Ferrer, V. P., et al. (2015). Brown Spider (Loxosceles Genus) Venom Toxins: Evaluation of Biological Conservation by Immune Cross-Reactivity. Toxicon 108, 154-166. doi:10.1016/j.toxicon.2015.09.041

Cai, W., Fujita, T., Hidaka, Y., Jin, H., Suita, K., Shigeta, M., et al. (2019). Translationally Controlled Tumor Protein (TCTP) Plays a Pivotal Role in Cardiomyocyte Survival through a Bnip3-dependent Mechanism. Cell Death Dis 10, 549. doi:10.1038/s41419-019-1787-7

Calabria, P., Shimokawa-Falcão, L., Colombini, M., Moura-da-Silva, A., Barbaro, K., Faquim-Mauro, E., et al. (2019). Design and Production of a Recombinant Hybrid Toxin to Raise Protective Antibodies against Loxosceles Spider Venom. Toxins 11, 108-121. doi:10.3390/toxins 11020108

Calderón-Pérez, B., Xoconostle-Cázares, B., Lira-Carmona, R., Hernández-Rivas, R., Ortega-López, J., and Ruiz-Medrano, R. (2014). The Plasmodium Falciparum Translationally Controlled Tumor Protein (TCTP) Is Incorporated More Efficiently into B Cells Than its Human Homologue. PLoS One 9, e85514-6. doi:10.1371/journal.pone.0085514

Calmette, A. (1986).Le Venin des Serpents, Physiologie de L'envenimation, Traitement des Morsures Venimeuses par le Sérum des Animaux Vaccinés. Paris: Société D'éditions Science.

Cardoso, F. C., Dekan, Z., Smith, J. J., Deuis, J. R., Vetter, I., Herzig, V., et al. (2017). Modulatory Features of the Novel Spider Toxin $\mu$-TRTX-Dfla Isolated from the Venom of the spiderDavus Fasciatus. Br. J. Pharmacol. 174, 2528-2544. doi:10.1111/bph.13865

Catalán, A., Cortes, W., Sagua, H., González, J., and Araya, J. E. (2011). Two New Phospholipase D Isoforms of Loxosceles Laeta: Cloning, Heterologous Expression, Functional Characterization, and Potential Biotechnological Application. J. Biochem. Mol. Toxicol. 25, 393-403. doi:10.1002/jbt.20399

Chaim, O. M., Sade, Y. B., Da Silveira, R. B., Toma, L., Kalapothakis, E., ChávezOlórtegui, C., et al. (2006). Brown Spider Dermonecrotic Toxin Directly Induces Nephrotoxicity. Toxicol. Appl. Pharmacol. 211, 64-77. doi:10.1016/ j.taap.2005.05.015

Chaim, O. M., Trevisan-Silva, D., Chaves-Moreira, D., Wille, A. C. M., Ferrer, V. P., Matsubara, F. H., et al. (2011). Brown Spider (Loxosceles Genus) Venom Toxins: Tools for Biological Purposes. Toxins 3, 309-344. doi:10.3390/ toxins 3030309

Chao, K. L., Muthukumar, L., and Herzberg, O. (2007). Structure of Human Hyaluronidase-1, a Hyaluronan Hydrolyzing Enzyme Involved in Tumor Growth and Angiogenesis $\dagger, \ddagger$. Biochemistry 46, 6911-6920. doi:10.1021/ bi700382g

Chaves-Moreira, D., Chaim, O. M., Sade, Y. B., Paludo, K. S., Gremski, L. H., Donatti, L., et al. (2009). Identification of a Direct Hemolytic Effect Dependent on the Catalytic Activity Induced by Phospholipase-D (Dermonecrotic Toxin) from Brown Spider Venom. J. Cel. Biochem. 107, 655-666. doi:10.1002/ jcb. 22148

Chaves-Moreira, D., de Moraes, F. R., Caruso, Í. P., Chaim, O. M., Senff-Ribeiro, A., Ullah, A., et al. (2017). Potential Implications for Designing Drugs against the Brown Spider Venom Phospholipase-D. J. Cel. Biochem. 118, 726-738. doi: $10.1002 /$ jcb. 25678

Chaves-Moreira, D., Souza, F. N., Fogaça, R. T. H., Mangili, O. C., Gremski, W., Senff-Ribeiro, A., et al. (2011). The Relationship between Calcium and the Metabolism of Plasma Membrane Phospholipids in Hemolysis Induced by Brown Spider Venom Phospholipase-D Toxin. J. Cel. Biochem. 112, 2529-2540. doi: $10.1002 /$ jcb. 23177

Choi, S.-J., Parent, R., Guillaume, C., Deregnaucourt, C., Delarbre, C., Ojcius, D. M., et al. (2004). Isolation and Characterization of Psalmopeotoxin I and II: Two Novel Antimalarial Peptides from the Venom of the tarantulaPsalmopoeus Cambridgei. FEBS Lett. 572, 109-117. doi:10.1016/ j.febslet.2004.07.019

Clement, H., Olvera, A., Rodríguez, M., Zamudio, F., Palomares, L. A., Possani, L. D., et al. (2012). Identification, cDNA Cloning and Heterologous Expression of a Hyaluronidase from the Tarantula Brachypelma Vagans Venom. Toxicon 60, 1223-1227. doi:10.1016/j.toxicon.2012.08.018

Clemente, M., Corigliano, M., Pariani, S., Sánchez-López, E., Sander, V., and Ramos-Duarte, V. (2019). Plant Serine Protease Inhibitors: Biotechnology 
Application in Agriculture and Molecular Farming. Ijms 20, 1345. doi:10.3390/ ijms20061345

Costa, H. P. S., Oliveira, J. T. A., Sousa, D. O. B., Morais, J. K. S., Moreno, F. B., Monteiro-Moreira, A. C. O., et al. (2014). JcTI-I: a Novel Trypsin Inhibitor from Jatropha Curcas Seed Cake with Potential for Bacterial Infection Treatment. Front. Microbiol. 5, 1-12. doi:10.3389/fmicb.2014.00005

Costa, T. G. F., Costal-Oliveira, F., de Assis, T. C. S., Lima, S. A., Martins, C. A., Finco, A. B., et al. (2020). Engineered Antigen Containing Epitopes from Loxosceles Spp. Spider Toxins Induces a Monoclonal Antibody (Lox-mAb3) against Astacin-like Metalloproteases. Int. J. Biol. Macromolecules 162, 490-500. doi:10.1016/j.ijbiomac.2020.06.176

Cramer, J. A., Bailey, L. C., Bailey, C. A., and Miller, R. T. (1994). Kinetic and Mechanistic Studies with Bovine Testicular Hyaluronidase. Biochim. Biophys. Acta (Bba) - Gen. Subjects 1200, 315-321. doi:10.1016/0304-4165(94)90173-2

da Saúde, M. (2020). Acidente por animais peçonhentos - Notificações registradas no Sistema de Informação de Agravos de Notificação - Brasil. SINAN. Available at:http://tabnet.datasus.gov.br/cgi/deftohtm.exe?sinannet/cnv/animaisbr.def.

Da Silva, P. H., Da Silveira, R. B., Helena Appel, M., Mangili, O. C., Gremski, W., and Veiga, S. S. (2004). Brown Spiders and Loxoscelism. Toxicon 44, 693-709. doi:10.1016/j.toxicon.2004.07.012

da Silva, T. P., de Castro, F. J., Vuitika, L., Polli, N. L. C., Antunes, B. C., BóiaFerreira, M., et al. (2021). Brown Spiders' Phospholipases-D with Potential Therapeutic Applications: Functional Assessment of Mutant Isoforms. Biomedicines 9, 320. doi:10.3390/biomedicines 9030320

Da Silveira, R. B., Wille, A. C., Chaim, O. M., Appel, M. H., Silva, D. T., Franco, C. R., et al. (2007). Identification, Cloning, Expression and Functional Characterization of an Astacin-like Metalloprotease Toxin from Loxosceles Intermedia (Brown Spider) Venom. Biochem. J. 406, 355-363. doi:10.1042/ BJ20070363

De Almeida, D. M., Gondo-Higashi, H., Marcelino, J. R., Ho, P. L., de Azevedo, I. d. L. M. J., van den Berg, C., et al. (2008). A New Anti-loxoscelic Serum Produced against Recombinant Sphingomyelinase D: Results of Preclinical Trials. Am. J. Trop. Med. Hyg. 79, 463-470. doi:10.4269/ajtmh.2008.79.463

De Castro, C. S., Silvestre, F. G., Araújo, S. C., Yazbeck, G. D. M., Mangili, O. C., Cruz, I., et al. (2004). Identification and Molecular Cloning of Insecticidal Toxins from the Venom of the Brown Spider Loxosceles Intermedia. Toxicon 44, 273-280. doi:10.1016/j.toxicon.2004.05.028

de Salud, M. (2012). Guía de prevención, diagnóstico, tratamiento y vigilancia epidemiologica de los envenenamientos por arañas. Available at:https://bancos. salud.gob.ar/sites/default/files/2020-10/08-2012-guia-envenenamiento-aranas. pdf.69

De-Bona, E., Chaves-Moreira, D., Batista, T. B. D., Justa, H. C. d., Rossi, G. R., Antunes, B. C., et al. (2021). Production of a Novel Recombinant Brown Spider Hyaluronidase in Baculovirus-Infected Insect Cells. Enzyme Microb. Tech. 146, 109759. doi:10.1016/j.enzmictec.2021.109759

Dias-Lopes, C., Felicori, L., Guimarães, G., Gomes, E. R. M., Roman-Campos, D., Duarte, H., et al. (2010). Cardiotoxic Effects of Loxosceles Intermedia Spider Venom and the Recombinant Venom Toxin rLiD1. Toxicon 56, 1426-1435. doi:10.1016/j.toxicon.2010.08.008

Dias-Lopes, C., Felicori, L., Rubrecht, L., Cobo, S., Molina, L., Nguyen, C., et al. (2014). Generation and Molecular Characterization of a Monoclonal Antibody Reactive with Conserved Epitope in Sphingomyelinases D from Loxosceles Spider Venoms. Vaccine 32, 2086-2092. doi:10.1016/j.vaccine.2014.02.012

Dongol, Y., Caldas Cardoso, F., and Lewis, R. J. (2019). Spider Knottin Pharmacology at Voltage-Gated Sodium Channels and Their Potential to Modulate Pain Pathways. Toxins 11, 626. doi:10.3390/toxins11110626

Dos Santos, L., Dias, N., Roberto, J., Pinto, A., and Palma, M. (2009). Brown Recluse Spider Venom: Proteomic Analysis and Proposal of a Putative Mechanism of Action. Ppl. Available at:http://www.ncbi.nlm.nih.gov/ pubmed/19689420 16, 933-943. doi:10.2174/092986609788923383

Duarte, C. G., Bonilla, C., Guimarães, G., Machado De Avila, R. A., Mendes, T. M., Silva, W., et al. (2015). Anti-loxoscelic Horse Serum Produced against a Recombinant Dermonecrotic Protein of Brazilian Loxosceles Intermedia Spider Neutralize Lethal Effects of Loxosceles Laeta Venom from Peru. Toxicon 93, 37-40. doi:10.1016/j.toxicon.2014.10.023

Echols, R. M. (2012). A Long and Winding Road; Evolution of Antimicrobial Drug Development - Crisis Management. Expert Rev. Anti-infective Ther. 10, 1311-1319. doi:10.1586/eri.12.131
Farooqui, A. A., and Srivastava, P. N. (1979). Novel Affinity Chromatographic Methods for Purification of $\beta$-N-acetylhexosaminidase from Rabbit Sperm Cytoplasmic Droplets. Int. J. Biochem. 10, 745-748. doi:10.1016/0020-711X(79) 90152-6

Feitosa, L., Gremski, W., Veiga, S. S., Elias, M. C. Q. B., Graner, E., Mangili, O. C., et al. (1998). Detection and Characterization of Metalloproteinases with Gelatinolytic, Fibronectinolytic and Fibrinogenolytic Activities in Brown Spider (Loxosceles Intermedia) Venom. Toxicon 36, 1039-1051. doi:10.1016/ S0041-0101(97)00083-4

Felicori, L., Fernandes, P. B., Giusta, M. S., Duarte, C. G., Kalapothakis, E., Nguyen, C., et al. (2009). An In Vivo Protective Response against Toxic Effects of the Dermonecrotic Protein from Loxoscelesintermedia Spider Venom Elicited by Synthetic Epitopes. Vaccine 27, 4201-4208. doi:10.1016/ j.vaccine.2009.04.038

Fernandes Pedrosa, M. D. F., Junqueira de Azevedo, I. D. L. M., Gonçalves-deAndrade, R. M., Van Den Berg, C. W., Ramos, C. R. R., Lee Ho, P., et al. (2002). Molecular Cloning and Expression of a Functional Dermonecrotic and Haemolytic Factor from Loxosceles Laeta Venom. Biochem. Biophysical Res. Commun. 298, 638-645. doi:10.1016/S0006-291X(02)02521-4

Fernandes-Pedrosa, M. d. F., Junqueira-de-Azevedo, I. d. L., Gonçalves-deAndrade, R. M., Kobashi, L. S., Almeida, D. D., Ho, P. L., et al. (2008). Transcriptome Analysis of Loxosceles Laeta (Araneae, Sicariidae) Spider Venomous Gland Using Expressed Sequence Tags. BMC Genomics 9, 279. doi:10.1186/1471-2164-9-279

Ferrer, V. P., de Mari, T. L., Gremski, L. H., Trevisan Silva, D., da Silveira, R. B., Gremski, W., et al. (2013). A Novel Hyaluronidase from Brown Spider (Loxosceles Intermedia) Venom (Dietrich's Hyaluronidase): From Cloning to Functional Characterization. Plos Negl. Trop. Dis. 7, e2206-12. doi:10.1371/journal.pntd.0002206

Figueiredo, L. F. M., Dias-Lopes, C., Alvarenga, L. M., Mendes, T. M., Machado-deÁvila, R. A., McCormack, J., et al. (2014). Innovative Immunization Protocols Using Chimeric Recombinant Protein for the Production of Polyspecific Loxoscelic Antivenom in Horses. Toxicon 86, 59-67. doi:10.1016/ j.toxicon.2014.05.007

Fingermann, M., de Roodt, A. R., Cascone, O., and Miranda, M. V. (2020). Biotechnological Potential of Phospholipase D for Loxosceles Antivenom Development. Toxicon: X 6, 100036. doi:10.1016/j.toxcx.2020.100036

Fitches, E. C., Pyati, P., King, G. F., and Gatehouse, J. A. (2012). Fusion to Snowdrop Lectin Magnifies the Oral Activity of Insecticidal $\omega$-Hexatoxin-Hvla Peptide by Enabling its Delivery to the Central Nervous System. PLoS One 7, e39389. doi:10.1371/journal.pone.0039389

Fitches, E., Edwards, M. G., Mee, C., Grishin, E., Gatehouse, A. M. R., Edwards, J. P., et al. (2004). Fusion Proteins Containing Insect-specific Toxins as Pest Control Agents: Snowdrop Lectin Delivers Fused Insecticidal Spider Venom Toxin to Insect Haemolymph Following Oral Ingestion. J. Insect Physiol. 50, 61-71. doi:10.1016/j.jinsphys.2003.09.010

Frost, G. I. (2007). Recombinant Human Hyaluronidase (rHuPH20): An Enabling Platform for Subcutaneous Drug and Fluid Administration. Expert Opin. Drug Deliv. 4, 427-440. doi:10.1517/17425247.4.4.427

Fujita, T., Felix, K., Pinkaew, D., Hutadilok-Towatana, N., Liu, Z., and Fujise, K. (2008). Human Fortilin Is a Molecular Target of Dihydroartemisinin. FEBS Lett. 582, 1055-1060. doi:10.1016/j.febslet.2008.02.055

Futrell, J. M. (1992). Loxoscelism. Am. J. Med. Sci. 304, 261-267. doi:10.1097/ 00000441-199210000-00008

Gaci, N., Dobrijevic, D., Boudebbouze, S., Moumen, B., Maguin, E., and Rhimi, M. (2013). Biotechnological Applications of Serpin: an Update. Recent Adv. DNA Gene Seq. 7. doi:10.2174/1872215611307020008

Gettins, P. G. W. (2002). Serpin Structure, Mechanism, and Function. Chem. Rev. 102, 4751-4804. doi:10.1021/cr010170+

Girish, K. S., and Kemparaju, K. (2007). The Magic Glue Hyaluronan and its Eraser Hyaluronidase: A Biological Overview. Life Sci. 80, 1921-1943. doi:10.1016/ j.lfs.2007.02.037

Girish, K. S., Shashidharamurthy, R., Nagaraju, S., Gowda, T. V., and Kemparaju, K. (2004). Isolation and Characterization of Hyaluronidase a "Spreading Factor" from Indian Cobra (Naja naja) Venom. Biochimie 86, 193-202. doi:10.1016/j.biochi.2004.02.004

Gomez, H. F., Miller, M. J., Trachy, J. W., Marks, R. M., and Warren, J. S. (1999). Intradermal Anti-loxosceles Fab Fragments Attenuate Dermonecrotic 
Arachnidism. Acad. Emerg. Med 6, 1195-1202. doi:10.1111/j.15532712.1999.tb00133.x

Graeff, Z. S., Nowatzki, J., de Bona, E., Da Justa, H. C., Gremski, L. H., and Veiga, S. S. (2019). Molecular Cloning and Characterization of a Serpin from Loxosceles Intermedia Venom Gland. Toxicon 168, S10. doi:10.1016/ j.toxicon.2019.06.060

Gremski, L. H., Da Justa, H. C., Da Silva, T. P., Polli, N. L. C., Antunes, B. C., Minozzo, J. C., et al. (2020). Forty Years of the Description of Brown Spider Venom Phospholipases-D. Toxins 12, 164. doi:10.3390/toxins12030164

Gremski, L. H., Da Silveira, R. B., Chaim, O. M., Probst, C. M., Ferrer, V. P., Nowatzki, J., et al. (2010). A Novel Expression Profile of the Loxosceles Intermedia Spider Venomous Gland Revealed by Transcriptome Analysis. Mol. Biosyst. 6, 2403-2416. doi:10.1039/c004118a

Gremski, L. H., Trevisan-Silva, D., Ferrer, V. P., Matsubara, F. H., Meissner, G. O., Wille, A. C. M., et al. (2014). Recent Advances in the Understanding of Brown Spider Venoms: From the Biology of Spiders to the Molecular Mechanisms of Toxins. Toxicon 83, 91-120. doi:10.1016/j.toxicon.2014.02.023

Hawgood, B. J. (1992). Pioneers of Anti-venomous Serotherapy: Dr Vital Brazil (1865-1950). Toxicon 30, 573-579. doi:10.1016/0041-0101(92)90851-u

Helm, S., and Racz, G. B. (2019). Hyaluronidase in Neuroplasty: A Review. Pain Physician 22, 555-560. doi:10.36076/ppj/2019.22.e555

Herzig, V., Ikonomopoulou, M., Smith, J. J., Dziemborowicz, S., Gilchrist, J., KuhnNentwig, L., et al. (2016). Molecular Basis of the Remarkable Species Selectivity of an Insecticidal Sodium Channel Toxin from the African Spider Augacephalus Ezendami. Sci. Rep. 6, 1-11. doi:10.1038/srep29538

Herzig, V., and King, G. (2015). The Cystine Knot Is Responsible for the Exceptional Stability of the Insecticidal Spider Toxin $\omega$-Hexatoxin-Hvla. Toxins 7, 4366-4380. doi:10.3390/toxins7104366

Hobbs, G. D., Anderson, A. R., Greene, T. J., and Yealy, D. M. (1996). Comparison of Hyperbaric Oxygen and Dapsone Therapy for Loxosceles Envenomation. Acad. Emerg. Med. 3, 758-761. doi:10.1111/j.1553-2712.1996.tb03511.x

Hogan, C. J., Barbaro, K. C., and Winkel, K. (2004). Loxoscelism: Old Obstacles, New Directions. Ann. Emerg. Med. 44, 608-624. doi:10.1016/ j.annemergmed.2004.08.028

Horta, C. C. R., Magalhães, B. d. F., Oliveira-Mendes, B. B. R., Carmo, A. O. d., Duarte, C. G., Felicori, L. F., et al. (2014). Molecular, Immunological, and Biological Characterization of Tityus Serrulatus Venom Hyaluronidase: New Insights into its Role in Envenomation. Plos Negl. Trop. Dis. 8, e2693. doi:10.1371/journal.pntd.0002693

Houben, A. J. S., and Moolenaar, W. H. (2011). Autotaxin and LPA Receptor Signaling in Cancer. Cancer Metastasis Rev. 30, 557-565. doi:10.1007/s10555011-9319-7

Huntington, J. A. (2011). Serpin Structure, Function and Dysfunction. J. Thromb. Haemost. 9, 26-34. doi:10.1111/j.1538-7836.2011.04360.x

Isbister, G. K., and Fan, H. W. (2011). Spider Bite. The Lancet 378, 2039-2047. doi:10.1016/S0140-6736(10)62230-1

Jeon, H.-J., Cui, X.-S., Guo, J., Lee, J. M., Kim, J.-S., and Oh, J. S. (2017). TCTP Regulates Spindle Assembly during Postovulatory Aging and Prevents Deterioration in Mouse Oocyte Quality. Biochim. Biophys. Acta (Bba) - Mol. Cel Res. 1864, 1328-1334. doi:10.1016/j.bbamcr.2017.05.002

Justa, H. C. d., Matsubara, F. H., de-Bona, E., Schemczssen-Graeff, Z., Polli, N. L. C., de Mari, T. L., et al. (2020). LALLT (Loxosceles Allergen-like Toxin) from the Venom of Loxosceles Intermedia: Recombinant Expression in Insect Cells and Characterization as a Molecule with Allergenic Properties. Int. J. Biol. Macromolecules 164, 3984-3999. doi:10.1016/j.ijbiomac.2020.08.212

Kalapothakis, E., Araujo, S. C., De Castro, C. S., Mendes, T. M., Gomez, M. V., Mangili, O. C., et al. (2002). Molecular Cloning, Expression and Immunological Properties of LiD1, a Protein from the Dermonecrotic Family of Loxosceles Intermedia Spider Venom. Toxicon 40, 1691-1699. doi:10.1016/S00410101(02)00201-5

Karim-Silva, S., Becker-Finco, A., Jiacomini, I. G., Boursin, F., Leroy, A., Noiray, M., et al. (2020). Loxoscelism: Advances and Challenges in the Design of Antibody Fragments with Therapeutic Potential. Toxins 12, 256. doi:10.3390/ toxins 12040256

Karim-Silva, S., Moura, J. d., Noiray, M., Minozzo, J. C., Aubrey, N., Alvarenga, L. M., et al. (2016). Generation of Recombinant Antibody Fragments with ToxinNeutralizing Potential in Loxoscelism. Immunol. Lett. 176, 90-96. doi:10.1016/ j.imlet.2016.05.019
Kawakami, Y., Kasakura, K., and Kawakami, T. (2019). Histamine-Releasing Factor, a New Therapeutic Target in Allergic Diseases. Cells 8, 1515 doi:10.3390/cells8121515

Kaya, M. O., Arslan, O., and Guler, O. O. (2015). A New Affinity Method for Purification of Bovine Testicular Hyaluronidase Enzyme and an Investigation of the Effects of Some Compounds on This Enzyme. J. Enzyme Inhib. Med. Chem. 30, 524-527. doi:10.3109/14756366.2014.949253

Kedjarune-Leggat, U., Saetan, U., Khongsaengkaeo, A., Suwannarat, S., Deachamag, P., Wonglapsuwan, M., et al. (2020). Biological Activities of a Recombinant Fortilin from Fenneropenaeus Merguiensis. PLoS One 15, e0239672-16. doi:10.1371/journal.pone.0239672

Kemparaju, K., and Girish, K. S. (2006). Snake Venom Hyaluronidase: A Therapeutic Target. Cell Biochem. Funct. 24, 7-12. doi:10.1002/cbf.1261

Khan, N., Niazi, Z. R., Rehman, F. u., Akhtar, A., Khan, M. M., Khan, S., et al. (2018). Hyaluronidases: A Therapeutic Enzyme. Ppl 25, 663-676. doi:10.2174/ 0929866525666180629121823

Kimura, T., Ono, S., and Kubo, T. (2012). Molecular Cloning and Sequence Analysis of the cDNAS Encoding Toxin-like Peptides from the Venom Glands of Tarantula Grammostola Rosea. Int. J. Peptides 2012, 1-10. doi:10.1155/2012/731293

King, G. F. (2019). Tying Pest Insects in Knots: the Deployment of Spider-venomderived Knottins as Bioinsecticides. Pest Manag. Sci. 75, 2437-2445. doi:10.1002/ps.5452

Kintzing, J. R., and Cochran, J. R. (2016). Engineered Knottin Peptides as Diagnostics, Therapeutics, and Drug Delivery Vehicles. Curr. Opin. Chem. Biol. 34, 143-150. doi:10.1016/j.cbpa.2016.08.022

Kniker, W. T., Morgan, P. N., Flanigan, W. J., Reagan, P. W., and Dillaha, C. J. (1969). An Inhibitor of Complement in the Venom of the Brown Recluse Spider, Loxosceles Reclusa. Exp. Biol. Med. 131, 1432-1434. doi:10.3181/ 00379727-131-34124

Kusma, J., Chaim, O. M., Wille, A. C. M., Ferrer, V. P., Sade, Y. B., Donatti, L., et al. (2008). Nephrotoxicity Caused by Brown Spider Venom Phospholipase-D (Dermonecrotic Toxin) Depends on Catalytic Activity. Biochimie 90, 1722-1736. doi:10.1016/j.biochi.2008.07.011

Lane, L., McCoppin, H. H., and Dyer, J. (2011). Acute Generalized Exanthematous Pustulosis and Coombs-Positive Hemolytic Anemia in a Child Following Loxosceles Reclusa Envenomation. Pediatr. Dermatol. 28, 685-688. doi:10.1111/j.1525-1470.2010.01302.x

Lévano, J., and Fernández, R. (2004). Diagnóstico y Tratamiento de los accidentes por animales ponzoñosos. Inst. Nac. SALUD Cent. Nac. Prod. Biológicos.

Lima, S. d. A., Guerra-Duarte, C., Costal-Oliveira, F., Mendes, T. M., Figueiredo, L. F. M., Oliveira, D., et al. (2018). Recombinant Protein Containing B-Cell Epitopes of Different Loxosceles Spider Toxins Generates Neutralizing Antibodies in Immunized Rabbits. Front. Immunol. 9, 653. doi:10.3389/ fimmu.2018.00653

Linhart, B., and Valenta, R. (2012). Vaccines for Allergy. Curr. Opin. Immunol. 24, 354-360. doi:10.1016/j.coi.2012.03.006

Lopes, P. H., Squaiella-Baptistão, C. C., Marques, M. O. T., and Tambourgi, D. V. (2020). Clinical Aspects, Diagnosis and Management of Loxosceles Spider Envenomation: Literature and Case Review. Arch. Toxicol. 94, 1461-1477. doi:10.1007/s00204-020-02719-0

Lucas, A., Yaron, J. R., Zhang, L., and Ambadapadi, S. (2018). erine Protease Assays: Measuring the Enzyme Targets for Serpins, Serine Protease Inhibitors. In Methods In Molecular Biology. Springer Science+Business Media, 267-274. doi:10.1007/978-1-4939-8645-3S

Lyon, M., and Phelps, C. F. (1981). A Rapid Purification of Bovine Testicular Hyaluronidase by Chromatography on Dermatan Sulphate-Substituted 1,6Diaminohexane-Sepharose 4B. Biochem. J. 199, 419-426. doi:10.1042/ bj1990419

MacDonald, S. (2012). Potential Role of Histamine Releasing Factor (HRF) as a Therapeutic Target for Treating Asthma and Allergy. Jaa, 51-59. doi:10.2147/ JAA.S28868

Machado, L. F., Laugesen, S., Botelho, E. D., Ricart, C. A. O., Fontes, W., Barbaro, K. C., et al. (2005). Proteome Analysis of Brown Spider Venom: Identification of Loxnecrogin Isoforms in Loxosceles Gaucho Venom. Proteomics 5, 2167-2176. doi:10.1002/pmic.200401096

Maeng, J., Kim, H. Y., Shin, D. H., and Lee, K. (2013). Transduction of Translationally Controlled Tumor Protein Employing TCTP-Derived 
Protein Transduction Domain. Anal. Biochem. 435, 47-53. doi:10.1016/ j.ab.2012.11.029

Magalhães, G. S., Caporrino, M. C., Della-Casa, M. S., Kimura, L. F., Prezotto-Neto, J. P., Fukuda, D. A., et al. (2013). Cloning, Expression and Characterization of a Phospholipase D from Loxosceles Gaucho Venom Gland. Biochimie 95, 1773-1783. doi:10.1016/j.biochi.2013.06.002

Magalhães, M. R., da Silva, N. J., and Ulhoa, C. J. (2008). A Hyaluronidase from Potamotrygon Motoro (Freshwater Stingrays) Venom: Isolation and Characterization. Toxicon 51, 1060-1067. doi:10.1016/j.toxicon.2008.01.008

Makris, M., Spanoudaki, N., Giannoula, F., Chliva, C., Antoniadou, A., and Kalogeromitros, D. (2009). Acute Generalized Exanthematous Pustulosis (AGEP) Triggered by a Spider Bite. Allergol. Int. 58, 301-303. doi:10.2332/ allergolint.08-CR-0035

Malaque, C. M. S., Santoro, M. L., Cardoso, J. L. C., Conde, M. R., Novaes, C. T. G., Risk, J. Y., et al. (2011). Clinical Picture and Laboratorial Evaluation in Human Loxoscelism. Toxicon 58, 664-671. doi:10.1016/j.toxicon.2011.09.011

Manríquez, J. J., and Silva, S. (2009). Cutaneous and Visceral Loxoscelism: a Systematic Review. Rev. Chil. Infectol. 26, 420-432.

Marathe, K. R., Patil, R. H., Vishwakarma, K. S., Chaudhari, A. B., and Maheshwari, V. L. (2019). Protease Inhibitors and Their Applications: An Overview. 1st ed. Elsevier B.V., 211-242. doi:10.1016/B978-0-444-64185-4.00006-X

Matsubara, F. H., Gremski, L. H., Meissner, G. O., Constantino Lopes, E. S., Gremski, W., Senff-Ribeiro, A., et al. (2013). A Novel ICK Peptide from the Loxosceles Intermedia (Brown Spider) Venom Gland: Cloning, Heterologous Expression and Immunological Cross-Reactivity Approaches. Toxicon 71, 147-158. doi:10.1016/j.toxicon.2013.05.014

Matsubara, F. H., Meissner, G. O., Herzig, V., Justa, H. C., Dias, B. C. L., TrevisanSilva, D., et al. (2017). Insecticidal Activity of a Recombinant Knottin Peptide fromLoxosceles Intermediavenom and Recognition of These Peptides as a Conserved Family in the Genus. Insect Mol. Biol. 26, 25-34. doi:10.1111/ imb. 12268

Meissner, G. O., de Resende Lara, P. T., Scott, L. P. B., Braz, A. S. K., ChavesMoreira, D., Matsubara, F. H., et al. (2016). Molecular Cloning and In Silico Characterization of Knottin Peptide, U2-SCRTX-Lit2, from Brown Spider (Loxosceles Intermedia) Venom Glands. J. Mol. Model. 22, 196. doi:10.1007/ s00894-016-3067-0

Mendes, T. M., Oliveira, D., Figueiredo, L. F. M., Machado-de-Avila, R. A., Duarte, C. G., Dias-Lopes, C., et al. (2013). Generation and Characterization of a Recombinant Chimeric Protein (rCpLi) Consisting of B-Cell Epitopes of a Dermonecrotic Protein from Loxosceles Intermedia Spider Venom. Vaccine 31, 2749-2755. doi:10.1016/j.vaccine.2013.03.048

Menzel, E. J., and Farr, C. (1998). Hyaluronidase and its Substrate Hyaluronan: Biochemistry, Biological Activities and Therapeutic Uses. Cancer Lett. 131, 3-11. doi:10.1016/S0304-3835(98)00195-5

Miranda, A. L. S. d., de, Guerra-Duarte, C., Guerra-Duarte, S. d. A., ChávezOlórtegui, C., and Soto-Blanco, B. (2021). History, Challenges and Perspectives on Loxosceles (Brown Spiders) Antivenom Production in Brazil. Toxicon 192, 40-45. doi:10.1016/j.toxicon.2021.01.004

Moore, S. J., Leung, C. L., Norton, H. K., and Cochran, J. R. (2013). Engineering Agatoxin, a Cystine-Knot Peptide from Spider Venom, as a Molecular Probe for In Vivo Tumor Imaging. PLoS One 8, e60498. doi:10.1371/journal.pone.0060498

Morey, S. S., Kiran, K. M., and Gadag, J. R. (2006). Purification and Properties of Hyaluronidase from Palamneus Gravimanus (Indian Black Scorpion) Venom. Toxicon 47, 188-195. doi:10.1016/j.toxicon.2005.10.014

Moura, J. De., Felicori, L., Moreau, V., Guimarães, G., Dias-lopes, C., and Molina, L. (2011). Protection against the Toxic Effects of Loxosceles Intermedia Spider Venom Elicited by Mimotope Peptides. Vaccine 29, 7992-8001. doi:10.1016/ j.vaccine.2011.08.065

Mulenga, A., and Azad, A. F. (2005). The Molecular and Biological Analysis of Ixodid Ticks Histamine Release Factors. Exp. Appl. Acarol. 37, 215-229. doi:10.1007/s10493-005-3261-8

Nakasu, E. Y. T., Williamson, S. M., Edwards, M. G., Fitches, E. C., Gatehouse, J. A., Wright, G. A., et al. (2014). Novel Biopesticide Based on a Spider Venom Peptide Shows No Adverse Effects on Honeybees. Proc. R. Soc. B. 281, 20140619. doi:10.1098/rspb.2014.0619

Norton, R. S., and Pallaghy, P. K. (1998). The Cystine Knot Structure of Ion Channel Toxins and Related Polypeptides. Toxicon 36, 1573-1583. doi:10.1016/ S0041-0101(98)00149-4
Olvera, A., Ramos-Cerrillo, B., Estévez, J., Clement, H., de Roodt, A., PaniaguaSolís, J., et al. (2006). North and South American Loxosceles Spiders: Development of a Polyvalent Antivenom with Recombinant Sphingomyelinases D as Antigens. Toxicon 48, 64-74. doi:10.1016/ j.toxicon.2006.04.010

Ospedal, K. Z., Appel, M. H., Neto, J. F., Mangili, O. C., Veiga, S. S., and Gremski, W. (2002). Histopathological Findings in Rabbits after Experimental Acute Exposure to the Loxosceles Intermedia (Brown Spider) Venom. Int. J. Exp. Pathol. 83, 287-294. doi:10.1046/j.1365-2613.2002.00241.x

Pauli, I., Minozzo, J. C., Henrique da Silva, P., Chaim, O. M., and Veiga, S. S. (2009). Analysis of Therapeutic Benefits of Antivenin at Different Time Intervals after Experimental Envenomation in Rabbits by Venom of the Brown Spider (Loxosceles Intermedia). Toxicon 53, 660-671. doi:10.1016/ j.toxicon.2009.01.033

Poh, C. H., Yuen, R., Chung, M. C. M., and Khoo, H. E. (1992). Purification and Partial Characterization of Hyaluronidase from Stonefish (Synanceja Horrida) Venom. Comp. Biochem. Physiol. - Part. B Biochem. doi:10.1016/0305-0491(92) 90172-N

Pucca, M. B., Cerni, F. A., Janke, R., Bermúdez-Méndez, E., Ledsgaard, L., Barbosa, J. E., et al. (2019). History of Envenoming Therapy and Current Perspectives. Front. Immunol. 10, 1-13. doi:10.3389/fimmu.2019.01598

Sabotič, J., and Kos, J. (2012). Microbial and Fungal Protease Inhibitors-Ccurrent and Potential Applications. Appl. Microbiol. Biotechnol. 93, 1351-1375. doi:10.1007/s00253-011-3834-x

Sade, Y. B., Bóia-Ferreira, M., Gremski, L. H., Da Silveira, R. B., Gremski, W., SenffRibeiro, A., et al. (2012). Molecular Cloning, Heterologous Expression and Functional Characterization of a Novel Translationally-Controlled Tumor Protein (TCTP) Family Member from Loxosceles Intermedia (Brown Spider) Venom. Int. J. Biochem. Cel Biol. 44, 170-177. doi:10.1016/ j.biocel.2011.10.013

Saez, N. J., Senff, S., Jensen, J. E., Er, S. Y., Herzig, V., Rash, L. D., et al. (2010). Spider-venom Peptides as Therapeutics. Toxins 2, 2851-2871. doi:10.3390/ toxins 2122851

Said, A., Hmiel, P., Goldsmith, M., Dietzen, D., and Hartman, M. E. (2014). Successful Use of Plasma Exchange for Profound Hemolysis in a Child with Loxoscelism. Pediatrics 134, e1464-e1467. doi:10.1542/peds.2013-3338

Sams, H. H., Dunnick, C. A., Smith, M. L., and King, L. E. (2001). Necrotic Arachnidism. J. Am. Acad. Dermatol. 44, 561-576. doi:10.1067/ mjd.2001.112385

Sánchez-Olivas, M. A., Valencia-Zavala, M. P., Sánchez-Olivas, J. A., SepulvedaVelázquez, G., and Vega-Robledo, G. (2011). [Cutaneous Necrotic Loxoscelism. A Case Report]. Rev. Alerg. Mex. 58, 171-176.

Sangsuwan, J., Wanichpakorn, S., and Kedjarune-Leggat, U. (2015). Translationally Controlled Tumor Protein Supplemented Chitosan Modified Glass Ionomer Cement Promotes Osteoblast Proliferation and Function. Mater. Sci. Eng. C 54, 61-68. doi:10.1016/j.msec.2015.04.036

Schemczssen-Graeff, Z., Justa, H. C. d., Nowatzki, J., Baldissera, A. B., Polli, N. L. C., De-Bona, E., et al. (2021). Description of a Serpin Toxin in Loxosceles (Brown Spider) Venoms: Cloning, Expression in Baculovirus-Infected Insect Cells and Functional Characterization. Int. J. Biol. Macromolecules 183, 1607-1620. doi:10.1016/j.ijbiomac.2021.05.129

Searle, T., Ali, F. R., and Al-Niaimi, F. (2020). Hyaluronidase in Dermatology: Uses beyond Hyaluronic Acid Fillers. J. Drugs Dermatol. 19, JO01020. doi:10.36849/ jdd.2020.5416

Segura-Ramírez, P., and Silva Júnior, P. (2018). Loxosceles Gaucho Spider Venom: An Untapped Source of Antimicrobial Agents. Toxins 10, 522. doi:10.3390/ toxins 10120522

Senff-Ribeiro, A., Henrique da Silva, P., Chaim, O. M., Gremski, L. H., Paludo, K. S., Bertoni da Silveira, R., et al. (2008). Biotechnological Applications of Brown Spider (Loxosceles Genus) Venom Toxins. Biotechnol. Adv. 26, 210-218. doi:10.1016/j.biotechadv.2007.12.003

Silverstein, S. M., Greenbaum, S., and Stern, R. (2012). Hyaluronidase in Ophthalmology. J. Appl. Res. 12, 1-13.

Siqueira, R. A. G. B., Calabria, P. A. L., Caporrino, M. C., Tavora, B. C. L. F., Barbaro, K. C., Faquim-mauro, E. L., et al. (2019). When Spider and Snake Get along: Fusion of a Snake Disintegrin with a Spider Phospholipase D to Explore Their Synergistic Effects on a Tumor Cell. Toxicon 168, 40-48. doi:10.1016/j.toxicon.2019.06.225 
Soldatova, L. N., Tsai, C., Dobrovolskaia, E., Marković-Housley, Z., and Slater, J. E. (2007). Characterization of the N-Glycans of Recombinant Bee Venom Hyaluronidase (Api M 2) Expressed in Insect Cells. Allergy Asthma Proc. 28, 210-215. doi:10.2500/aap.2007.28.2947

Souza, N. A., Dias-Lopes, C., Matoso, I. H. G., de Oliveira, C. F. B., ChávezOlortegui, C. D., Minozzo, J. C., et al. (2018). Immunoprotection Elicited in Rabbit by a Chimeric Protein Containing B-Cell Epitopes of Sphingomyelinases D from Loxosceles Spp. Spiders. Vaccine 36, 7324-7330. doi:10.1016/ j.vaccine.2018.10.035

Sudarshan, S., and Dhananjaya, B. L. (2016). Antibacterial Activity of an Acidic Phospholipase A2 (NN-XIb-PLA2) from the Venom of Naja naja (Indian Cobra). Springerplus 5, 1-7. doi:10.1186/s40064-016-1690-y

Tania, M., Khan, M. A., Zhang, H., Li, J., and Song, Y. (2010). Autotaxin: A Protein with Two Faces. Biochem. Biophysical Res. Commun. 401, 493-497. doi:10.1016/j.bbrc.2010.09.114

Taylor, K. J., Van, T. T. H., Macdonald, S. M., Meshnick, S. R., Fernley, R. T., Macreadie, I. G., et al. (2015). Immunization of Mice withPlasmodiumTCTP Delays Establishment ofPlasmodiuminfection. Parasite Immunol. 37, 23-31. doi:10.1111/pim.12158

Trevisan-Silva, D., Bednaski, A. V., Fischer, J. S. G., Veiga, S. S., Bandeira, N., Guthals, A., et al. (2017). A Multi-Protease, Multi-Dissociation, Bottom-UpTo-Top-Down Proteomic View of the Loxosceles Intermedia Venom. Sci. Data 4, 1-7. doi:10.1038/sdata.2017.90

Trevisan-Silva, D., Gremski, L. H., Chaim, O. M., da Silveira, R. B., Meissner, G. O., Mangili, O. C., et al. (2010). Astacin-like Metalloproteases Are a Gene Family of Toxins Present in the Venom of Different Species of the Brown Spider (Genus Loxosceles). Biochimie 92, 21-32. doi:10.1016/j.biochi.2009.10.003

Van Regenmortel, M. H. V. (1996). Mapping Epitope Structure and Activity: From One-Dimensional Prediction to Four-Dimensional Description of Antigenic Specificity. Methods 9, 465-472. doi:10.1006/meth.1996.0054

Veiga, S. S., Da Silveira, R. B., Dreyfuss, J. L., Haoach, J., Pereira, A. M., Mangili, O. C., et al. (2000). Identification of High Molecular Weight Serine-Proteases in Loxosceles Intermedia (Brown Spider) Venom. Toxicon 38, 825-839. doi:10.1016/S0041-0101(99)00197-X

Vuitika, L., Chaves-Moreira, D., Caruso, I., Lima, M. A., Matsubara, F. H., Murakami, M. T., et al. (2016). Active Site Mapping of Loxosceles Phospholipases D: Biochemical and Biological Features. Biochim. Biophys. Acta (Bba) - Mol. Cel Biol. Lipids 1861, 970-979. doi:10.1016/j.bbalip.2016.05.009

Wanachottrakul, N., Chotigeat, W., and Kedjarune-Leggat, U. (2011). Translationally Controlled Tumor Protein against Apoptosis from 2-
Hydroxy-Ethyl Methacrylate in Human Dental Pulp Cells. J. Mater. Sci. Mater. Med. 22, 1479-1487. doi:10.1007/s10856-011-4328-1

Weber, G. C., Buhren, B. A., Schrumpf, H., Wohlrab, J., and Gerber, P. A. (2019). "Clinical Applications of Hyaluronidase," in Therapeutic Enzymes: Function and Clinical Implications. Athens: Springer, 255-277. doi:10.1007/978-981-137709-9_12

Wille, A. C. M., Chaves-Moreira, D., Trevisan-Silva, D., Magnoni, M. G., BoiaFerreira, M., Gremski, L. H., et al. (2013). Modulation of Membrane Phospholipids, the Cytosolic Calcium Influx and Cell Proliferation Following Treatment of B16-F10 Cells with Recombinant Phospholipase-D from Loxosceles Intermedia (Brown Spider) Venom. Toxicon 67, 17-30. doi:10.1016/j.toxicon.2013.01.027

Windley, M. J., Herzig, V., Dziemborowicz, S. A., Hardy, M. C., King, G. F., and Nicholson, G. M. (2012). Spider-venom Peptides as Bioinsecticides. Toxins 4, 191-227. doi:10.3390/toxins4030191

World Spider Catalog. Version 22.0 (2021). World Spider Catalog. Version 22.0. Nat. Hist. Mus. Bern. doi:10.24436/2

Young, A. R., and Pincus, S. J. (2001). Comparison of Enzymatic Activity from Three Species of Necrotising Arachnids in Australia: Loxosceles Rufescens, Badumna Insignis and Lampona Cylindrata. Toxicon 39, 391-400. doi:10.1016/ S0041-0101(00)00145-8

Zanetti, V. C., Da Silveira, R. B., Dreyfuss, J. L., Haoach, J., Mangili, O. C., Veiga, S. S., et al. (2002). Morphological and Biochemical Evidence of Blood Vessel Damage and Fibrinogenolysis Triggered by Brown Spider Venom. Blood Coagul. Fibrinolysis 13, 135-148. doi:10.1097/00001721-200203000-00009

Zobel-Thropp, P. A., Correa, S. M., Garb, J. E., and Binford, G. J. (2014). Spit and Venom from Scytodes Spiders: A Diverse and Distinct Cocktail. J. Proteome Res. 13, 817-835. doi:10.1021/pr400875s

Conflict of Interest: The authors declare that the research was conducted in the absence of any commercial or financial relationships that could be construed as a potential conflict of interest.

Copyright (C) 2021 Gremski, Matsubara, Polli, Antunes, Schluga, Justa, Minozzo, Wille, Senff-Ribeiro and Veiga. This is an open-access article distributed under the terms of the Creative Commons Attribution License (CC BY). The use, distribution or reproduction in other forums is permitted, provided the original author(s) and the copyright owner(s) are credited and that the original publication in this journal is cited, in accordance with accepted academic practice. No use, distribution or reproduction is permitted which does not comply with these terms. 